\title{
Emission and transport of bromocarbons: from the West Pacific ocean into the stratosphere
}

\author{
S. Tegtmeier ${ }^{1}$, K. Krüger ${ }^{1}$, B. Quack ${ }^{1}$, E. L. Atlas ${ }^{2}$, I. Pisso ${ }^{3}$, A. Stohl ${ }^{4}$, and X. Yang ${ }^{5,6}$ \\ ${ }^{1}$ GEOMAR Helmholtz Centre for Ocean Research Kiel, Kiel, Germany \\ ${ }^{2}$ Rosenstiel School of Marine and Atmospheric Science, University of Miami, Miami, Florida, USA \\ ${ }^{3}$ Research Institute for Global Change, JAMSTEC, Yokohama, Japan \\ ${ }^{4}$ Norwegian Institute for Air Research (NILU), Kjeller, Norway \\ ${ }^{5}$ National Centre for Atmospheric Science (NCAS-Climate), Cambridge, UK \\ ${ }^{6}$ Centre for Atmospheric Science, Department of Chemistry, University of Cambridge, Cambridge, UK
}

Correspondence to: S. Tegtmeier (stegtmeier@geomar.de)

Received: 12 January 2012 - Published in Atmos. Chem. Phys. Discuss.: 8 February 2012

Revised: 12 September 2012 - Accepted: 16 October 2012 - Published: 16 November 2012

\begin{abstract}
Oceanic emissions of halogenated very short-lived substances (VSLS) are expected to contribute significantly to the stratospheric halogen loading and therefore to ozone depletion. The amount of VSLS transported into the stratosphere is estimated based on in-situ observations around the tropical tropopause layer (TTL) and on modeling studies which mostly use prescribed global emission scenarios to reproduce observed atmospheric concentrations. In addition to upper-air VSLS measurements, direct observations of oceanic VSLS emissions are available along ship cruise tracks. Here we use such in-situ observations of VSLS emissions from the West Pacific and tropical Atlantic together with an atmospheric Lagrangian transport model to estimate the direct contribution of bromoform $\left(\mathrm{CHBr}_{3}\right)$, and dibromomethane $\left(\mathrm{CH}_{2} \mathrm{Br}_{2}\right)$ to the stratospheric bromine loading as well as their ozone depletion potential. Our emissionbased estimates of VSLS profiles are compared to upperair observations and thus link observed oceanic emissions and in situ TTL measurements. This comparison determines how VSLS emissions and transport in the cruise track regions contribute to global upper-air VSLS estimates. The West Pacific emission-based profiles and the global upper-air observations of $\mathrm{CHBr}_{3}$ show a relatively good agreement indicating that emissions from the West Pacific provide an average contribution to the global $\mathrm{CHBr}_{3}$ budget. The tropical Atlantic, although also being a $\mathrm{CHBr}_{3}$ source region, is of less importance for global upper-air $\mathrm{CHBr}_{3}$ estimates as revealed by the small emission-based abundances in the TTL.
\end{abstract}

Western Pacific $\mathrm{CH}_{2} \mathrm{Br}_{2}$ emission-based estimates are considerably smaller than upper-air observations as a result of the relatively low sea-to-air flux found in the West Pacific. Together, $\mathrm{CHBr}_{3}$ and $\mathrm{CH}_{2} \mathrm{Br}_{2}$ emissions from the West $\mathrm{Pa}$ cific are projected to contribute to the stratospheric bromine budget with $0.4 \mathrm{pptv} \mathrm{Br}$ on average and $2.3 \mathrm{pptv} \mathrm{Br}$ for cases of maximum emissions through product and source gas injection. These relatively low estimates reveal that the tropical West Pacific, although characterized by strong convective transport, might overall contribute less VSLS to the stratospheric bromine budget than other regions as a result of only low $\mathrm{CH}_{2} \mathrm{Br}_{2}$ and moderate $\mathrm{CHBr}_{3}$ oceanic emissions.

\section{Introduction}

Organic brominated compounds, emitted at the surface through natural and anthropogenic processes, are the primary source of stratospheric bromine. While brominated substances are transported through the troposphere and stratosphere, inorganic bromine $\left(\mathrm{Br}_{\mathrm{y}}\right)$ is released via photolysis or reaction with $\mathrm{OH}$. Once released the reactive bromine species are known to participate in catalytic ozone destruction in the stratosphere (McElroy et al., 1986; Solomon et al., 1995; Garcia and Solomon, 1994) and may also have a significant impact on tropospheric ozone (von Glasow et al., 2004; Yang et al., 2005). 
Long-lived bromocarbons with chemical lifetimes of years are well mixed in the troposphere and transported into the stratosphere without any significant chemical loss. In contrast, very short-lived substances (VSLS) have chemical lifetimes of less than 6 months (e.g., Ko and Poulet et al., 2003) and are often oxidized or photolyzed in the troposphere. If the VSLS reach the stratosphere before being photochemically destroyed they provide an in-situ source of stratospheric $\mathrm{Br}_{\mathrm{y}}$ upon their degradation. The cross-tropopause transport of VSLS is referred to as source gas injection (SGI). In case the VSLS are destroyed in the troposphere inorganic bromine is produced which is soluble and can be removed from the troposphere by wet deposition. If however, the inorganic product gases are transported into the stratosphere before being washed out, a process referred to as product gas injection (PGI), they will add to the stratospheric $\mathrm{Br}_{\mathrm{y}}$ budget. The dehydration of air masses during troposphere-to-stratosphere transport is not completely understood so far and therefore estimates of the wet deposition of $\mathrm{Br}_{\mathrm{y}}$ are highly uncertain (Montzka and Reimann et al., 2011). In particular, the impact of heterogeneous chemistry releasing bromine back to the gas phase on the efficiency of wet deposition as a sink for $\mathrm{Br}_{\mathrm{y}}$ is currently under discussion (Salawitch, 2006; Aschmann et al., 2011). Overall, the rate of SGI and PGI depends strongly on the efficiency of troposphere-stratosphere transport compared to the degradation of source gases (through photochemical loss) and product gases (through wet deposition). As a result, estimating the contribution of bromine containing VSLS to stratospheric $\mathrm{Br}_{\mathrm{y}}$ is by far more complicated than doing so for the long-lived bromocarbons.

Current measurement-based estimates of the VSLS contribution to stratospheric $\mathrm{Br}_{\mathrm{y}}$ range from 1.5 to $8 \mathrm{pptv}$ derived from balloon-borne measurements (Dorf et al., 2008), ground-based observations of column $\mathrm{BrO}$ (Sinnhuber et al., 2002, and references therein), and satellite $\mathrm{BrO}$ measurements (Sinnhuber et al., 2005; Livesey et al., 2006; Sioris et al., 2006; McLinden et al., 2010). In addition to the estimates based on in situ and satellite observations several recent modeling studies are available which focus on bromoform $\left(\mathrm{CHBr}_{3}\right)$ and dibromomethan $\left(\mathrm{CH}_{2} \mathrm{Br}_{2}\right)$, the two most abundant short-lived bromocarbons (Law and Sturges et al., 2007). Their contribution to stratospheric $\mathrm{Br}_{\mathrm{y}}$ is estimated to be $\sim 2-5$ pptv (Kerkweg et al., 2008; Gettelman et al., 2009; Aschmann et al., 2009; Hossaini et al., 2010; Liang et al., 2010; Ordóñez et al., 2012) which is less than suggested by observations. A modeling study from Warwick et al. (2006) taking into account all five major short-lived bromocarbons yields estimates of 6-7 pptv. The model studies either used prescribed removal timescales for $\mathrm{Br}_{\mathrm{y}}$ in the TTL or explicitly calculate the $\mathrm{Br}_{\mathrm{y}}$ removal based on dehydration processes in the model. There are large differences in the effect of washout predicted by models which together with the lack of observations of bromine $\mathrm{PG}$ in the TTL result in a wide range of $\mathrm{CHBr}_{3}$ and $\mathrm{CH}_{2} \mathrm{Br}_{2}$ PGI from 0.4 to 3.9 ppt. Together observations and model studies suggest a VSLS contribu- tion of $5 \pm 3$ ppt as a currently best estimate (Montzka and Reimann et al., 2011). The upper limit of SGI and PGI estimates obtained from observations and models would imply a relatively large impact of stratospheric inorganic bromine produced from VSLS $\left(\mathrm{Br}_{\mathrm{y}}^{\mathrm{VSLS}}\right)$ on midlatitude ozone depletion (Salawitch et al., 2005). Therefore the extent to which VSLS contribute to the stratospheric $\mathrm{Br}_{\mathrm{y}}$ budget remains a key question of ongoing research.

$\mathrm{CHBr}_{3}$ and $\mathrm{CH}_{2} \mathrm{Br}_{2}$ are expected to account for a large fraction of stratospheric $\mathrm{Br}_{\mathrm{y}}^{\mathrm{VSLS}}$. The uncertainty in the contribution of the two VSLS to stratospheric $\mathrm{Br}_{\mathrm{y}}$ originates partially from the uncertainty in the efficiency of SGI and PGI and partially from strongly variable sources. $\mathrm{CHBr}_{3}$ is mainly produced in the ocean by marine life forms such as macro algae and phytoplankton (e.g., Carpenter and Liss, 2000; Quack and Wallace, 2003), while $\mathrm{CH}_{2} \mathrm{Br}_{2}$ is a byproduct during the $\mathrm{CHBr}_{3}$ formation (Tokarczyk and Moore, 1994). The oceanic production and thereafter the ocean-toatmosphere flux of $\mathrm{CHBr}_{3}$ is spatially and temporal highly variable with tropical, subtropical and shelf waters being identified as potentially important source regions (Quack et al., 2004, 2007; Butler et al., 2007). Observational estimates of local oceanic emissions of the two VSLS are based on measurements of surface water and atmospheric concentration data. In general, only data of limited spatial and temporal coverage are available. As a result, current estimates of oceanic emissions of $\mathrm{CHBr}_{3}$ and also of $\mathrm{CH}_{2} \mathrm{Br}_{2}$ show considerable variations (Montzka and Reimann et al., 2011 and references therein) and are a major source of uncertainty in atmospheric modeling studies. It is of interest to determine if global modeling studies, which often rely on uniformly mixed background mixing ratios, might miss the influence of strongly localized sources. This would be particularly problematic in case of a correlation between emission strength and efficiency of transport into the TTL, resulting in systematic over- or underestimates of PGI and SGI when using averaged emission fluxes. Due to the large regional differences in the $\mathrm{CHBr}_{3}$ emission rates and its short tropospheric lifetime of 15-30 days (Hossaini et al., 2010) compared to atmospheric transport time scales the tropospheric $\mathrm{CHBr}_{3}$ distribution is highly variable in time and space. $\mathrm{CH}_{2} \mathrm{Br}_{2}$ has a longer tropospheric lifetime (50-400 days) than $\mathrm{CHBr}_{3}$, however, not long enough to be well mixed in the troposphere. $\mathrm{CHBr}_{3}$ and $\mathrm{CH}_{2} \mathrm{Br}_{2}$ measurements in the upper troposphere and TTL region are available from a few aircraft and balloon campaigns (Schauffler et al., 1998; Wamsley et al., 1998; Schauffler et al., 1999; Sinnhuber and Folkins, 2006; Law and Sturges et al., 2007; Laube et al., 2008) and show a large spread. A current challenge is to relate the variability of observed VSLS sea-to-air fluxes to the variability of measured VSLS in the upper troposphere and TTL region.

In this study we use sea-to-air fluxes of $\mathrm{CHBr}_{3}$ and $\mathrm{CH}_{2} \mathrm{Br}_{2}$ obtained from ship-based measurements to estimate their SGI and PGI into the stratosphere. The measurements were done during the TransBrom Sonne cruise in the tropical 
West Pacific in 2009 as described in Sect. 2.1. The transport calculations are carried out with the Lagrangian particle dispersion model FLEXPART which is introduced in Sect. 2.2. Results of the transport calculations including estimates of the amount of VSLS, their degradation products transported into the TTL, and their ozone depletion potentials are presented in Sect. 3. Simulated $\mathrm{CHBr}_{3}$ and $\mathrm{CH}_{2} \mathrm{Br}_{2}$ vertical profiles are compared with aircraft observations. Analyzing how emission rates and convective activity influence SGI and PGI will help to understand the relative importance of these two processes for the stratospheric $\mathrm{Br}_{\mathrm{y}}$ budget.

\section{Data and model}

\subsection{Sonne TransBrom campaign}

Atmospheric and oceanic $\mathrm{CHBr}_{3}$ and $\mathrm{CH}_{2} \mathrm{Br}_{2}$ were measured during the TransBrom cruise with the R/V Sonne from Tomakomai, Japan, 9 October 2009 to Townsville, Australia, 23 October 2009 (Krüger and Quack, 2012). The time of the ship cruise was within the season of high typhoon occurrence in the tropical West Pacific, a region which is in general characterized by the globally highest convective activity ("warm pool") throughout the year. The cruise track crossed the typhoon Melor in the northern extratropics and the two tropical depressions Nepartak and Lupit. The transit route from Japan to Australia followed almost exactly the $146^{\circ}$ E meridian from $44^{\circ} \mathrm{N}$ to $18^{\circ} \mathrm{S}$ through extratropical and tropical regions. The TTL had a latitudinal extension from at least $36^{\circ} \mathrm{N}$ to $18^{\circ} \mathrm{S}$ during the time of the ship cruise.

Surface air samples were collected every 3 hours during the cruise section from $32.6^{\circ} \mathrm{N}$ to $18.7^{\circ} \mathrm{S}$ in pressurized stainless steel canisters. The air samples were analyzed subsequently for $\mathrm{CHBr}_{3}, \mathrm{CH}_{2} \mathrm{Br}_{2}$ and other VSLS at the Rosenstiel School of Marine and Atmospheric Sciences (RSMAS) in Miami by the group of Elliot Atlas following the method from Schauffler et al. (1999). Surface water samples were collected simultaneously by a submersible pump at $5 \mathrm{~m}$ depth and analyzed on board using a purge-andtrap GC/MS analytical system. A detailed description of the system can be found in Quack et al. (2004). The instantaneous sea-to-air flux of $\mathrm{CHBr}_{3}$ and $\mathrm{CH}_{2} \mathrm{Br}_{2}$ was calculated from the measured sea surface concentration and local atmospheric mixing ratios, Henry's law constant from Moore et al. (1995) and the instantaneous wind speed. The flux calculations are based on the transfer coefficient parameterization of Nightingale et al. (2000), which where adapted to $\mathrm{CHBr}_{3}$ and $\mathrm{CH}_{2} \mathrm{Br}_{2}$ (Quack and Wallace, 2003). Oceanic and atmospheric mixing ratios will be analyzed in detail in a future study (Quack et al., in preparation). Air concentrations of bromocarbons from this cruise were also reported by Brinckmann et al. (2012) using data from two separate sample collections. The two sample collections were analyzed in different laboratories (U. Frankfurt and RSMAS) and show excel- lent correlation. Only the RSMAS samples were used in the flux calculations.

\subsection{FLEXPART trajectories}

The atmospheric transport of $\mathrm{CHBr}_{3}$ and $\mathrm{CH}_{2} \mathrm{Br}_{2}$ from the oceanic surface into the upper troposphere and TTL is simulated with the Lagrangian particle dispersion model FLEXPART (Stohl et al., 2005). This model has been used extensively in studies of long-range and mesoscale transport (e.g., Spichtinger et al., 2001; Stohl et al., 2003; Forster et al., 2004). Validation of FLEXPART is based on comparisons with measurement data from three large-scale tracer experiments (Stohl et al., 1998) and on intercontinental air pollution transport studies (e.g., Stohl and Trickl, 1999; Forster et al., 2001; Spichtinger et al., 2001). FLEXPART is an offline model driven by meteorological fields from the ECMWF (European Centre for Medium-Range Weather Forecasts) numerical weather prediction model. It includes parameterizations for moist convection (Forster et al., 2007), turbulence in the boundary layer and free troposphere (Stohl and Thompson, 1999), dry deposition and in-cloud as well as belowcloud scavenging, and the simulation of chemical decay.

In order to describe the transport and dispersion of $\mathrm{CHBr}_{3}$, we simulate trajectories of a multitude of air parcels. For each data point of the observed sea-to-air flux a separate FLEXPART run is launched where 10000 air parcels were released over one hour from a $0.0002^{\circ} \times 0.0002^{\circ}$ grid box $\left(\sim 500 \mathrm{~m}^{2}\right)$ at the ocean surface centered at the measurement location. The total amount of $\mathrm{CHBr}_{3}$ emitted from this grid box over one hour is calculated based on the observationderived flux and uniformly distributed over the 10000 air parcels. The FLEXPART runs are driven by the ECMWF reanalysis product ERA-Interim (Dee et al., 2011) given at a horizontal resolution of $1^{\circ} \times 1^{\circ}$ on 60 model levels. Transport, dispersion and convection of the air parcels are calculated from the 6-hourly fields of horizontal and vertical wind, temperature, specific humidity, convective and large scale precipitation and others. The input data is retrieved from the ECMWF archives using a pre-processor which calculates the vertical wind in hybrid coordinates mass-consistently from spectral data. Trajectories were terminated after 3 months for $\mathrm{CHBr}_{3}$ and after $2 \mathrm{yr}$ for $\mathrm{CH}_{2} \mathrm{Br}_{2}$ according to their atmospheric life times.

Figure 1 illustrates a FLEXPART run for one case study based on the emitted $\mathrm{CHBr}_{3}$ flux observed during the TransBrom Sonne campaign at $19^{\circ} \mathrm{N}, 148^{\circ} \mathrm{E}$ on 14 October 2009 at 11 a.m. UTC. The spatial distribution of all 10000 air parcels on 24 October 2009, 10 days after their release from the measurement location, is displayed. A large fraction of the air parcels is spread out over the maritime continent, Southeast Asia, India, and the tropical Indian Ocean all the way from the west coast of Australia to the east coast of Africa. A smaller fraction of air parcels has been transported eastwards from the release location and is now distributed 


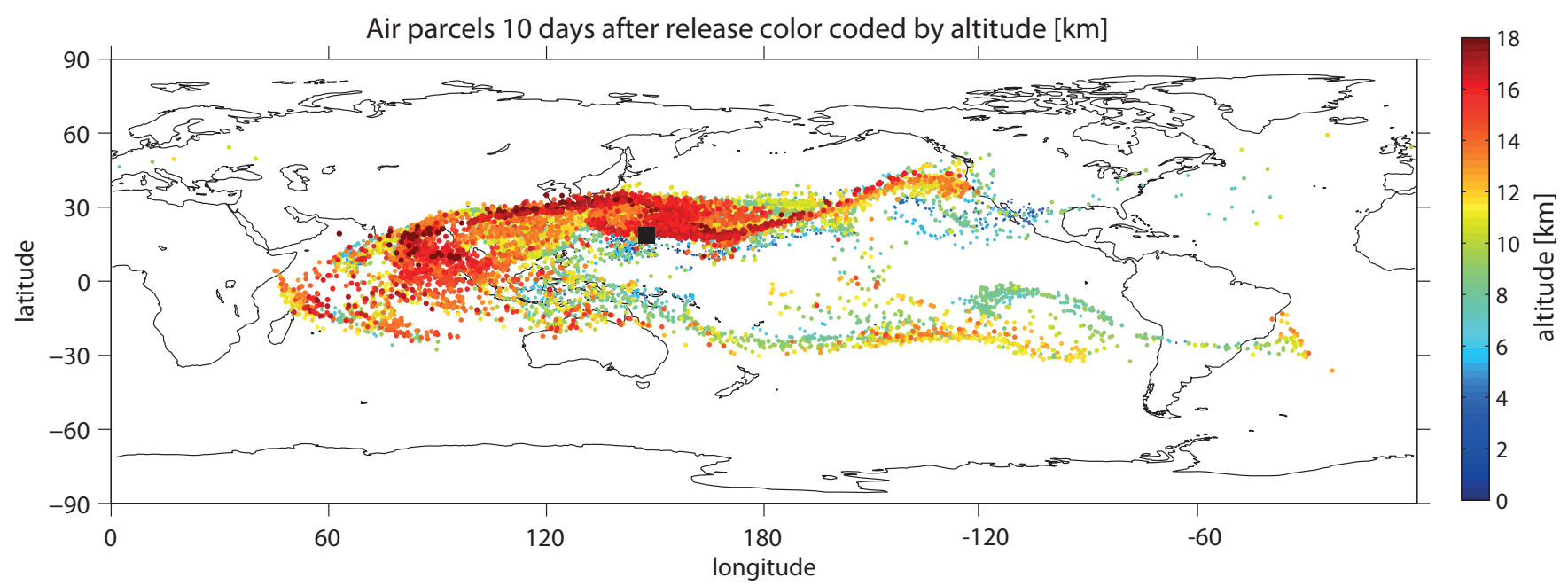

Fig. 1. Spatial distribution on 24 October 2009 , of air parcels originally released at the surface at $19^{\circ} \mathrm{N}, 148^{\circ} \mathrm{E}$ on 14 October 2009 , i.e. 10 days after their release. The air parcels are color coded by altitude. Air mass transport including convection has been calculated with the Lagrangian particle dispersion model FLEXPART.

along two narrow latitude bands at roughly $30^{\circ} \mathrm{N}$ and $30^{\circ} \mathrm{S}$ across the tropical Pacific. Overall, a large number of air parcels have reached altitudes above $10 \mathrm{~km}$ which illustrates the strong impact of deep convection on the vertical transport observed for this case study. Each air parcel carries an assigned mass of the $\mathrm{CHBr}_{3}$ tracer which is reduced at a rate corresponding to its chemical lifetime.

\subsection{Wet deposition of $\mathrm{Br}_{\mathrm{y}}$}

The degradation of $\mathrm{CHBr}_{3}$ and $\mathrm{CH}_{2} \mathrm{Br}_{2}$ along each trajectory is simulated by prescribing an altitude dependent chemical lifetime, ranging from 16 (50) days at the ocean surface to 29 (400) days in the TTL for $\mathrm{CHBr}_{3}\left(\mathrm{CH}_{2} \mathrm{Br}_{2}\right)$ (Hossaini et al., 2010). The fraction of photochemically destroyed $\mathrm{CHBr}_{3}$ and $\mathrm{CH}_{2} \mathrm{Br}_{2}$ contributes to the inorganic product gases which are grouped together as $\mathrm{Br}_{\mathrm{y}}$ and are transported together with the VSLS source gases along the trajectory. The assumption of instantaneous conversion between organic intermediate product gases and $\mathrm{Br}_{\mathrm{y}}$ has been shown to be reasonable (Hossaini et al., 2010). $\mathrm{Br}_{\mathrm{y}}$ can be removed effectively from the troposphere through wet scavenging by rain or ice (Yang et al., 2005). Wet deposition is initiated in FLEXPART if the relative humidity as calculated from meteorological input data exceeds $80 \%$ and the precipitation rate from ERAInterim is larger than zero. Within the family of inorganic bromine, $\mathrm{HOBr}$ and $\mathrm{HBr}$ can be washed out while the remaining species $\mathrm{Br}, \mathrm{BrO}, \mathrm{BrONO}_{2}$, and $\mathrm{Br}_{2}$ are not soluble. The washout in FLEXPART is modeled via the cloud scavenging ratio calculated with the help of the effective Henry's law coefficient, $\mathrm{H}_{\mathrm{eff}}$, which describes the physical solubility of a species as well as the effects of dissociation. Among the members of the $\mathrm{Br}_{\mathrm{y}}$ family, $\mathrm{HBr}$ has a very large acidity dissociation constant resulting in an effective Henry's law coef- ficient of $7.1 \times 10^{13} \mathrm{M} \mathrm{atm}^{-1}$ for $\mathrm{T}=298 \mathrm{~K}$ and $\mathrm{pH}=5$ (for details see Yang et al., 2005). While $\mathrm{HBr}$ provides the main pathway for wet removal of inorganic $\mathrm{Br}_{\mathrm{y}}, \mathrm{HOBr}$ is also soluble with $\mathrm{H}_{\mathrm{eff}}=6.1 \times 10^{3} \mathrm{M} \mathrm{atm}^{-1}$ due to its physical solubility but not due to dissociation (Frenzel et al., 1998).

In order to determine which fractions of $\mathrm{Br}_{\mathrm{y}}$ are in the form of $\mathrm{HBr}$ and $\mathrm{HOBr}$ and which fraction is not soluble we apply the $\mathrm{Br}_{\mathrm{y}}$ partitioning modeled with the Chemical Transport Model (CTM) p-TOMCAT (Yang et al., 2010). The model uses analysed wind-fields together with complex chemical schemes to simulate the tracer distribution in the troposphere and lower stratosphere. The partitiong of $\mathrm{Br}_{\mathrm{y}}$ in p-TOMCAT is done only for the gaseous phase and no apportionment of soluble species between gas and particulate phase is included. The 3-dimensional $\mathrm{Br}_{\mathrm{y}}$ field from $\mathrm{p}$-TOMCAT and its partitioning into $\mathrm{HOBr}, \mathrm{HBr}, \mathrm{Br}, \mathrm{BrO}, \mathrm{BrONO}_{2}$, and $\mathrm{Br}_{2}$ are given every $30 \mathrm{~min}$ for October 2009. The partitioning of the $\mathrm{Br}_{\mathrm{y}}$ field into the individual members of the $\mathrm{Br}_{\mathrm{y}}$ family varies strongly with location and time and is applied to every air parcel according to its location each time before the wet deposition is initiated. Wet deposition is then calculated individually for each inorganic bromine species based on its solubility specified by the effective Henry's law coefficient, as described above, in order to realistically simulate the overall $\mathrm{Br}_{\mathrm{y}}$ removal along the trajectories.

Heterogeneous chemical reactions of inorganic bromine species can release already dissolved bromine back to the gas phase (Abbatt, 2003; Iraci et al, 2005; Salawitch, 2006). This process can extend the tropospheric lifetime of $\mathrm{Br}_{\mathrm{y}}$ (von Glasow et al., 2004) by altering the efficiency of wet deposition. The chemical scheme of p-TOMCAT includes heterogeneous reactions on aerosols with reactivate bromine radicals from the reservoir species (Yang et al., 2005; 2010). The release of bromine back to the gas phase results in an 
elevated $\mathrm{BrO} / \mathrm{Br}_{\mathrm{y}}$ ratio (Yang et al., 2010) and thus a lower fraction of $\mathrm{Br}_{\mathrm{y}}$ is subject to wet deposition compared to a scenario without the heterogeneous chemical reactions. By directly using the p-TOMCAT $\mathrm{Br}_{\mathrm{y}}$ partitioning in the FLEXPART model runs these aerosol effects have been taken into consideration when simulating the wet removal of $\mathrm{Br}_{\mathrm{y}}$. Once wet deposition is initiated the $\mathrm{Br}_{\mathrm{y}}$ fraction determined to be washed out is removed completely and the release of dissolved $\mathrm{Br}_{\mathrm{y}}$ back to the atmosphere during evaporation is not taken into account by the modeling approach.

Uncertainties in the modeled wet deposition arise from uncertainties in the meteorological input data, from the parameterization of solubility via the effective Henry's law coefficient and from uncertainties in the $\mathrm{Br}_{\mathrm{y}}$ partitioning. Using the p-TOMCAT $\mathrm{Br}_{\mathrm{y}}$ partitioning field in FLEXPART leads in general to a more realistic simulation of $\mathrm{Br}_{\mathrm{y}}$ wet removal compared to assuming a fixed lifetime for the VSLS product gases. Uncertainties in the $\mathrm{Br}_{\mathrm{y}}$ partitioning can be caused by errors in the aerosols loading and in the mechanism used for heterogeneous reactions. Clouds and aerosols within pTOMCAT are not matched with those in FLEXPART which might lead to an additional error source. Given the overall uncertainties related to wet deposition of $\mathrm{Br}_{\mathrm{y}}$ including the role of heterogeneous chemistry, a sensitivity study is performed by assuming that $\mathrm{Br}_{\mathrm{y}}$ is insoluble with no additional sinks in order to derive an upper boundary of PGI delivery to the stratosphere based on observed oceanic emissions.

\subsection{Ozone Depletion Potential}

The Ozone Depletion Potential (ODP), a measure of a substance's destructive effects to the ozone layer relative to the reference substance $\mathrm{CFC}-11\left(\mathrm{CCl}_{3} \mathrm{~F}\right)$ is estimated for the short-lived species $\mathrm{CHBr}_{3}$ and $\mathrm{CH}_{2} \mathrm{Br}_{2}$. In general, the ODP of a long lived species $X$ can be calculated from:

$\mathrm{ODP}_{X}=\frac{M_{\mathrm{CFC}-11}}{M_{X}} \frac{a n_{\mathrm{Br}}+n_{\mathrm{Cl}}}{3} \frac{\tau_{X}}{\tau_{\mathrm{CFC}-11}}$

where $\tau$ is the global atmospheric lifetime, $M$ is the molecular weight, $n$ is the number of halogen atoms and $a$ is the effectiveness of ozone loss by bromine relative to ozone loss by chlorine. The concept of a global lifetime $\tau_{X}$ cannot be adapted to VSLS since only fractions of the originally released VSLS are injected into the stratosphere which depends on time and location of oceanic emission. Therefore, the global lifetime needs to be replaced by an expression weighting the fraction of VSLS reaching the tropopause and their subsequent residence time in the stratosphere.

The ODPs for $\mathrm{CHBr}_{3}$ and $\mathrm{CH}_{2} \mathrm{Br}_{2}$ are calculated as a function of location and time of emission $\left(x_{\mathrm{e}}, t_{\mathrm{e}}\right)$ following a trajectory-based method previously developed specifically for VSLS (Pisso et. al., 2010). Owing to the different timescales and processes in the troposphere and stratosphere, the estimates are based on separate ensembles of trajectories describing the transport in both regions. The same tropospheric trajectory ensembles used throughout the rest of the manuscript calculated for air masses emitted in the West Pacific in October 2009 (Sect. 2.2) are used to quantify the fraction of VSLS reaching the stratosphere at different injection points $(y, s)$. The stratospheric trajectories used in Pisso et al. (2010) run for a longer time period (20 years) to determine the stratospheric residence time. Pointwise ODPs were obtained from equation (1) where the expression $\int_{t_{\mathrm{e}}}^{\infty} \int_{\Omega} \sigma r_{X}^{\Omega} T^{\text {strat }} d y d s$ replaces $\tau_{X}$. This expression integrated in time $s$ starting at the emission time $t_{\mathrm{e}}$ and throughout the surface $\Omega$ (representing the tropopause) is estimated from the tropospheric and stratospheric trajectory ensembles. Tropospheric transport appears as the probability $\sigma\left(y, s ; x_{\mathrm{e}}, t_{\mathrm{e}}\right)$ of injection at $(y, s)$ in $\Omega$ while physicochemical processes in the troposphere appear as the injected proportion of total halogen emitted $r_{X}^{\Omega}\left(y, s ; x_{\mathrm{e}}, t_{\mathrm{e}}\right)$. Stratospheric transport is taken into account by $T^{\text {strat }}(y, s)$ and an ozone depletion efficiency factor of 60 is used for $\mathrm{Br}$ (Law and Sturges et al., 2007). A more detailed derivation of the approximations and parameterizations including a discussion of the errors involved can be found in Pisso et al. (2010).

\subsection{VSLS vertical profiles}

Based on our modeling approach (using observations obtained during localized ship campaigns) we prescribe lower boundary conditions only for the time and location of the measurement. As a result we derive localized quantities of VSLS emitted into the atmosphere and calculate transport and decay of these absolute VSLS amounts (given in units of mass) which cannot be easily compared to observations of mixing ratios. In order to enable such a comparison we use a simplified approach to calculate atmospheric mixing ratio profiles resulting from emission and transport properties above the West Pacific. The VSLS vertical profiles represent the VSLS mixing ratios averaged over all air parcels, which have been originally emitted at one measurement site, at the moment of their entrainment above a certain atmospheric level. The profiles are estimated from the overall amount of VSLS entrained above an atmospheric level, $m_{\mathrm{VSLS}}[\mathrm{kg}]$, together with the overall amount of air entrained above this level, $V_{\text {air }}\left[\mathrm{m}^{3}\right]$. In order to account for the fact that the VSLS emission grid box is very small while the air entrained above a certain level originates from all over the globe we calculate the fraction of $V_{\text {air }}$ that origins from the emission grid box, $V_{\text {airbox }}\left[\mathrm{m}^{3}\right]$. The mixing ratio, $c_{\mathrm{VSLS}}$, is calculated from:

$c_{\mathrm{VSLS}}=\frac{n_{\mathrm{VSLS}}}{n_{\mathrm{air}}}=\frac{m_{\mathrm{VSLS}} \cdot N_{A}}{V_{\mathrm{airbox}} \cdot M_{\mathrm{VSLS}} \cdot n_{\mathrm{air}}}$

with the number density of the VSLS $n_{\mathrm{VSLS}}$ [molecules $\mathrm{m}^{-3}$ ], the number density of air $n_{\text {air }}$ [molecules $\mathrm{m}^{-3}$ ], the molecular mass of the VSLS $M_{\mathrm{VSLS}}\left[\mathrm{kg} \mathrm{mol}^{-1}\right]$, and the Avogadro number $N_{A}$ 6.022 molecules $^{-1}{ }^{-1}$. Note that due to our modeling approach we cannot account for mixing with air masses 
a) $\mathrm{CHBr}_{3}-10$ days after release

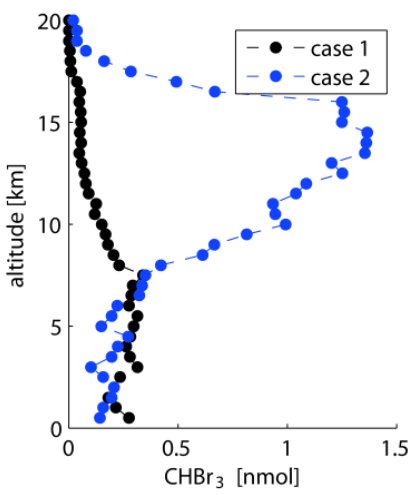

d) $\mathrm{CHBr}_{3}-10$ days after release

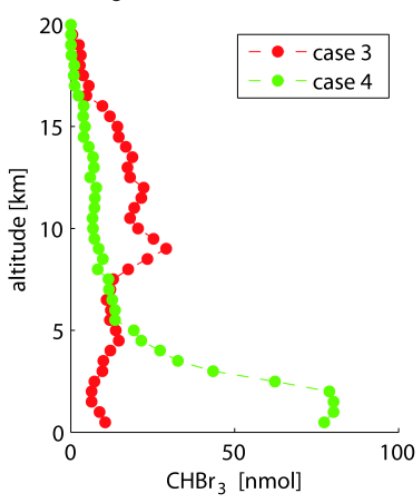

b) $\quad \mathrm{CHBr}_{3}-$ case 1

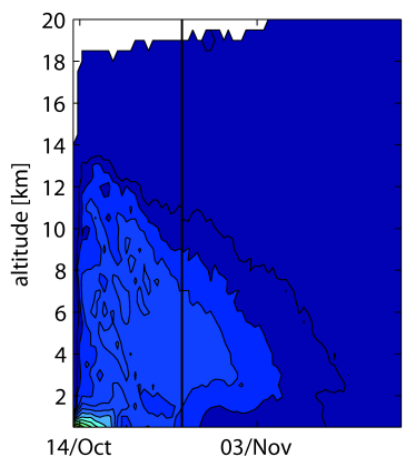

e) $\quad \mathrm{CHBr}_{3}-$ case 3

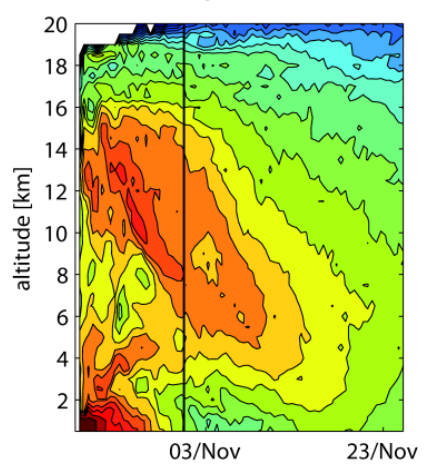

c) $\quad \mathrm{CHBr}_{3}-$ case 2

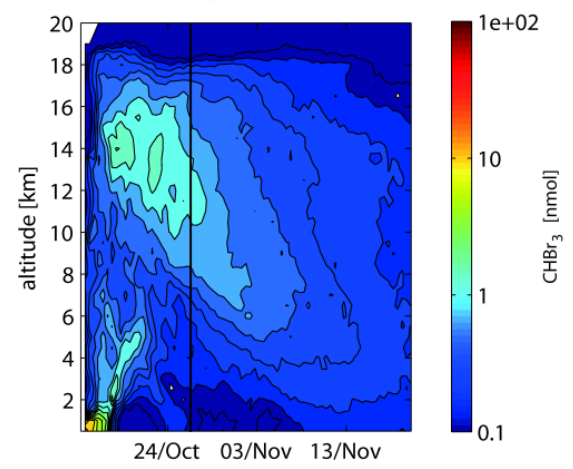

f) $\mathrm{CHBr}_{3}-$ case 4

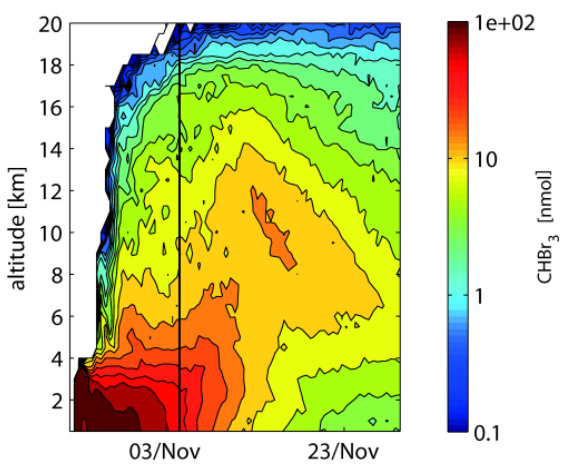

Fig. 2. The vertical distribution of tropical $\mathrm{CHBr}_{3}$ [nmol] 10 days after the release event is displayed for four case studies (a and d). Vertical distribution of tropical $\mathrm{CHBr}_{3}$ over a one month time period starting at the date of the release event is shown (b, $\mathbf{c}$, e, and f) with black lines indicating 10 days after the release event. The four case studies are based on observed $\mathrm{CHBr}_{3}$ sea-to-air fluxes at $24^{\circ} \mathrm{N}, 146^{\circ} \mathrm{E}$ on 13 October 2009 (case 1 ), at $19^{\circ} \mathrm{N}, 148^{\circ} \mathrm{E}$ on 14 October 2009 (case 2), at $3^{\circ} \mathrm{S}, 154^{\circ} \mathrm{E}$ on 19 October 2009 (case 3 ), and at $18^{\circ} \mathrm{S}, 145^{\circ} \mathrm{E}$ on 23 October 2009 (case 4).

from other regions. Therefore the profiles are not assumed to be real atmospheric profiles, but rather display profiles one would expect if one would assume emission and atmospheric transport properties as observed in the West Pacific globally. In other words our estimated profiles describe the relative contribution of West Pacific emissions to atmospheric VSLS mixing ratios. Uncertainties in our estimates of VSLS abundance in the upper TTL are associated with uncertainties in the convective parameterization, the vertical transport driven by the vertical wind fields, and the prescribed lifetime of the species. Testing the model sensitivity shows that our results are mainly constrained by the accurate representation of convection (which has been validated with tracer experiments and ${ }^{222} \mathrm{Rn}$ measurements in Forster et al., 2007), while small variations in the prescribed lifetime lead only to small differences in the derived VSLS profiles. Applying transport timescales based on vertical heating rates instead of vertical wind fields in the TTL between 15 and $17 \mathrm{~km}$ also results in only minor differences.

\section{Results}

\subsection{Case study of $\mathrm{CHBr}_{3}$ transport}

Four case studies of modeled $\mathrm{CHBr}_{3}$ transport which are characterized by highly variable emission and transport properties are analyzed. The first case study is based on an example of a very low $\mathrm{CHBr}_{3}$ sea-to-air flux of $39 \mathrm{pmol} \mathrm{m}^{-2} \mathrm{~h}^{-1}$ observed at $24^{\circ} \mathrm{N}, 146^{\circ} \mathrm{E}$ on 13 October 2009. The black line in Fig. 2a shows the vertical distribution of $\mathrm{CHBr}_{3} 10$ days after the release event which has been obtained by adding up the amount of trace gas contained in all tropical $\left(30^{\circ} \mathrm{N}-30^{\circ} \mathrm{S}\right)$ air parcels. The vertical distribution of $\mathrm{CHBr}_{3}$ peaks between surface and $7 \mathrm{~km}$ and only a very small fraction of the air masses has been transported into the TTL. Figure $2 b$ shows the vertical distribution of $\mathrm{CHBr}_{3}$ over a one month time period starting at the date of the release event on 13 October. Most air masses remain in the region below $8 \mathrm{~km}$ over the entire month due to the lack of deep convection. The second case study, displayed in Fig. 2c, is based on the $\mathrm{CHBr}_{3}$ sea-to-air flux observed at $19^{\circ} \mathrm{N}$, 
a)

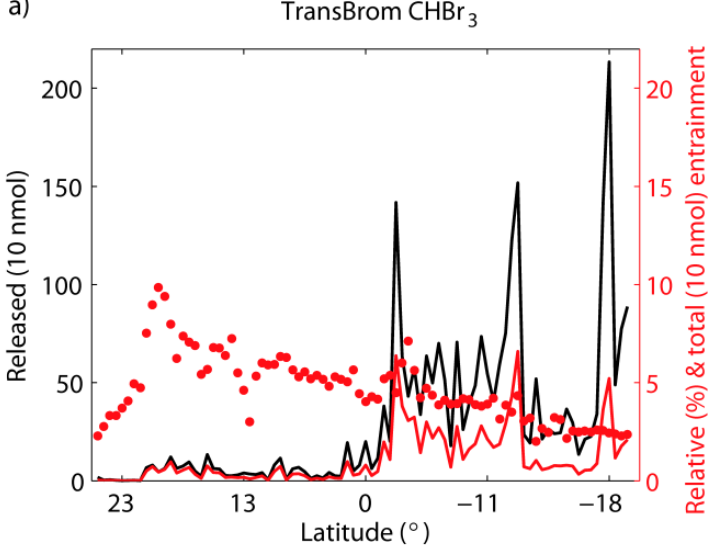

c)

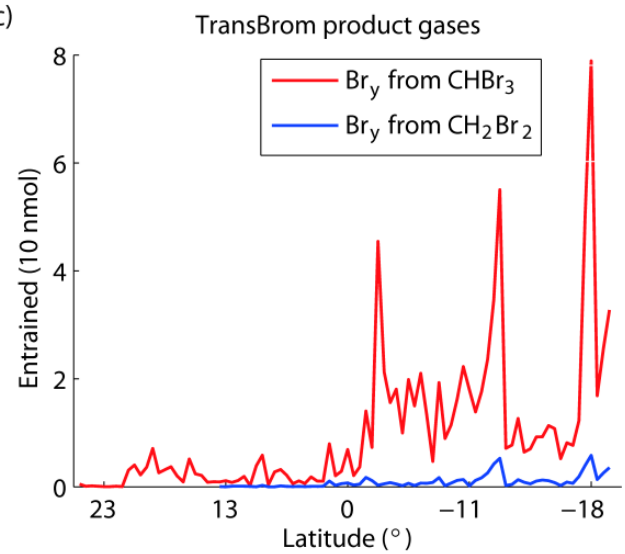

b)

TransBrom $\mathrm{CH}_{2} \mathrm{Br}_{2}$

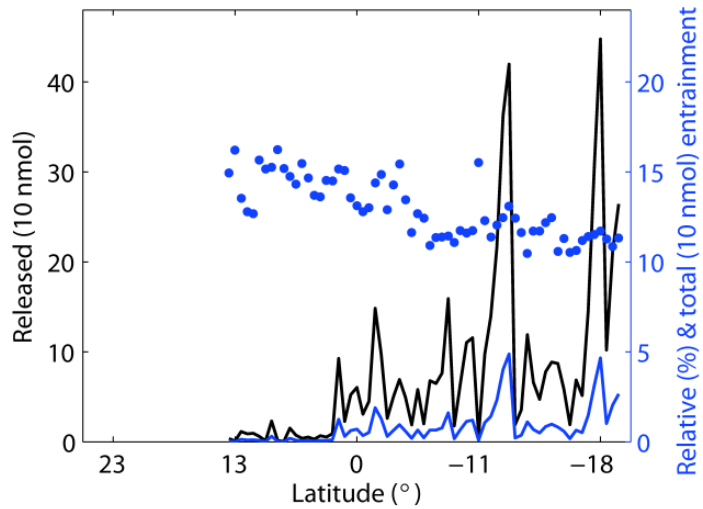

d)

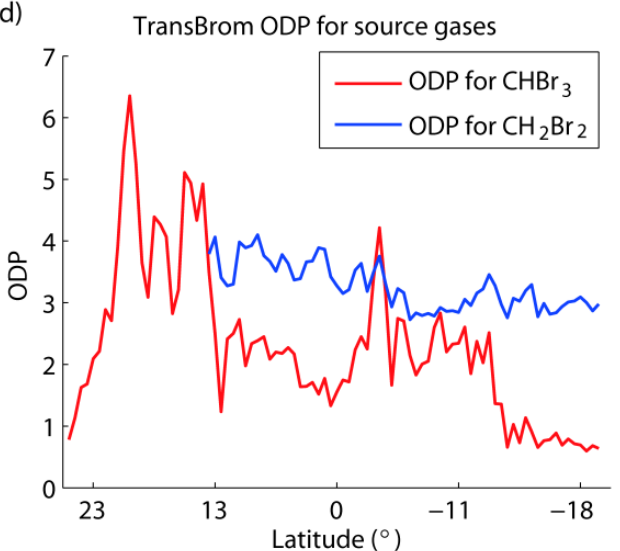

Fig. 3. Observed emissions of VSLS for one hour over $500 \mathrm{~m}^{2}$ (black line), and relative (colored dots) and total (colored line) amount of VSLS entrained above $17 \mathrm{~km}$ for $\mathrm{CHBr}_{3}$ (a) and $\mathrm{CH}_{2} \mathrm{Br}_{2}$ (b) are shown. PGI is given based on $\mathrm{CHBr}_{3}$ and $\mathrm{CH}_{2} \mathrm{Br}_{2}$ emissions (c). Ozone depletion potential as a function of emission location is displayed for both VSLS (d).

$148^{\circ} \mathrm{E}$ on 14 October 2009 which was also quite low with $133 \mathrm{pmol} \mathrm{m}^{-2} \mathrm{~h}^{-1}$. Air mass transport for this example has been discussed in Sect. 2.2 including the presentation of the spatial distribution of all air parcels 10 days after the release. The slowly decreasing concentrations of $\mathrm{CHBr}_{3}$ over time are caused by the chemical decay of the tracer. Also mixing into the extratropics will decrease the total amount of tropical $\mathrm{CHBr}_{3}$. However, Fig. 1 indicated that this process is weak and most air masses remain between $30^{\circ} \mathrm{N}$ and $30^{\circ} \mathrm{S}$. The total amount of $\mathrm{CHBr}_{3}$ entrained above a certain level is calculated as the sum of $\mathrm{CHBr}_{3}$ carried by all the trajectories which cross the respective level. For case study 2 the total amount of $\mathrm{CHBr}_{3}$ entrained above $17 \mathrm{~km}$ is $5.9 \mathrm{nmol}$. Compared to case study 1 this example shows quite a different behavior with strong upward transport of $\mathrm{CHBr}_{3}$ over a very short time period of only hours to days right after the release event as evident from the tracer distribution. The strong convective activity lifting the majority of the air masses is very likely related to the tropical depression observed close to the measurement location. A direct comparison of the vertical distribution of $\mathrm{CHBr}_{3} 10$ days after the release event between the two case studies can be seen in Fig. 2a illustrating the highly variable vertical distribution of $\mathrm{CHBr}_{3}$ as a result of the impact of deep convection.

Case study 3 is based on the sea-to-air flux observed at $3^{\circ} \mathrm{S}, 154^{\circ} \mathrm{E}$ on 19 October 2009 , while case study 4 describes the flux observed at $18^{\circ} \mathrm{S}, 145^{\circ} \mathrm{E}$ on 23 October 2009. Both case studies are chosen since they describe socalled hot-spot emissions with very high fluxes of 2876 and $4552 \mathrm{pmol} \mathrm{m}^{-2} \mathrm{~h}^{-1}$, respectively. The subsequent transport of the large amounts of $\mathrm{CHBr}_{3}$ develops very differently for the two events with case study 3 displaying strong convective events determining transport up to $14 / 15 \mathrm{~km}$ during the first 10 days (Fig. 2e), while case study 4 shows the strongest impact of convection below $10 \mathrm{~km}$ (Fig. 2f). A comparison 10 days after the release event reveals that for case study 4 most of the $\mathrm{CHBr}_{3}$ is still between 0 and $3 \mathrm{~km}$, while case study 3 results in most of the $\mathrm{CHBr}_{3}$ between 9 and $15 \mathrm{~km}$ (Fig. 2d). The four case studies demonstrate that we find a high variability in emission strength and transport intensity which will be analyzed systematically in the following paragraph. 


\subsection{SGI and PGI during the Sonne-TransBrom cruise}

Modeling of transport, chemical decay and wet deposition of $\mathrm{CHBr}_{3}, \mathrm{CH}_{2} \mathrm{Br}_{2}$ and $\mathrm{Br}_{\mathrm{y}}$ as described in Sect. 2 has been carried out for all observations of sea-to-air fluxes obtained during the TransBrom Sonne campaign. For each of the 88 observed $\mathrm{CHBr}_{3}$ and $64 \mathrm{CH}_{2} \mathrm{Br}_{2}$ fluxes a FLEXPART simulation analogous to the examples illustrated above was performed. Figure $3 a$ and $3 b$ show the oceanic emission rates (black lines) of the two major bromocarbons as observed during the ship campaign in the West Pacific. Note that the ocean has been a sink for $\mathrm{CHBr}_{3}$ north of $25^{\circ} \mathrm{N}$ and for $\mathrm{CH}_{2} \mathrm{Br}_{2}$ north of $15^{\circ} \mathrm{N}$. The oceanic emissions of both trace gases are characterized by a strong variability along the cruise track, linked to wind speed variations and differences in the compounds saturation state. Currently available global estimates of oceanic emissions of $\mathrm{CHBr}_{3}$ and $\mathrm{CH}_{2} \mathrm{Br}_{2}$ can differ approximately by a factor four and are highly uncertain (Montzka and Reimann et al., 2011). The mean emission rates observed in the West Pacific in October 2009 for $\mathrm{CHBr}_{3}$ of $608 \mathrm{pmol} \mathrm{m}^{-2} \mathrm{~h}^{-1}$ are approximately in the middle of global mean values ranging from $274 \mathrm{pmol} \mathrm{m}^{-2} \mathrm{~h}^{-1}$ (Carpenter and Liss, 2000) to $1041 \mathrm{pmol} \mathrm{m}^{-2} \mathrm{~h}^{-1}$ (Quack and Wallace, 2003; Butler et al., 2007). The mean rate for $\mathrm{CH}_{2} \mathrm{Br}_{2}$ of $164 \mathrm{pmol} \mathrm{m}^{-2} \mathrm{~h}^{-1}$ is only slightly larger than the lowest global estimate of $119 \mathrm{pmol} \mathrm{m}^{-2} \mathrm{~h}^{-1}$ (Yokouchi et al., 2005) and three times smaller than the largest global estimate of $547 \mathrm{pmol} \mathrm{m}^{-2} \mathrm{~h}^{-1}$ (Butler et al., 2007). The $\mathrm{CH}_{2} \mathrm{Br}_{2}$ mean emission rate is based on extremely low emissions observed during the first part of the cruise in the open ocean and on low to moderate emissions observed during the second part of the cruise which was more under coastal influence. In contrast $\mathrm{CHBr}_{3}$ emissions were also extremely low in the open ocean waters but higher during the second part of the cruise reaching emission strength expected for coastal regions.

The level above which no significant washout is expected is of special importance for SGI and PGI. VSLS product gases and source gases reaching this altitude can be assumed to contribute to the stratospheric halogen loading irrespective of their remaining chemical lifetime. While the exact level of the threshold above which no significant washout is expected is still under debate (Fueglistaler et al., 2009) we have chosen the cold point temperature at around $17 \mathrm{~km}$ as upper estimate of this level. The amount of VSLS product gases entrained above $17 \mathrm{~km}$ is calculated as the sum of $\mathrm{CHBr}_{3}$ or $\mathrm{CH}_{2} \mathrm{Br}_{2}$, respectively, carried by all the computational particles which cross this level.

For each observed oceanic VSLS emission along the cruise track we determine the fraction of the originally emitted amount of $\mathrm{CHBr}_{3}$ and $\mathrm{CH}_{2} \mathrm{Br}_{2}$ entrained above the $17 \mathrm{~km}$ surface. On average, these fractions range from $15 \%$ for $\mathrm{CH}_{2} \mathrm{Br}_{2}$ to $5 \%$ for $\mathrm{CHBr}_{3}$, indicating decreasing efficiency of vertical transport with decreasing lifetime. The time series of the entrained VSLS fractions as a function of latitude along the cruise track is displayed in Fig. 3a and b for
$\mathrm{CHBr}_{3}$ and $\mathrm{CH}_{2} \mathrm{Br}_{2}$, respectively (colored dots). Rapid vertical uplift in deep convection provides the major pathway for VSLS from the surface to the TTL. The variability of convection occurrence has a stronger impact on the shorter lived gas $\mathrm{CHBr}_{3}$ as evident from the variability of entrained VSLS fractions. We find the largest $\mathrm{CHBr}_{3}$ entrainment of up to $10 \%$ during the first part of the cruise at around $20^{\circ} \mathrm{N}$ related to the strong vertical uplift observed during the developing typhoon Lupit (Krüger and Quack, 2012). During the second part of the cruise vertical transport is less intense and therefore the fractional entrainment is lower reaching values between 2 and $5 \%$. For $\mathrm{CH}_{2} \mathrm{Br}_{2}$ the fractional entrainment is overall larger and shows less variability compared to $\mathrm{CHBr}_{3}$ as a result of the longer lifetime.

Together, the VSLS emissions and the transport efficiency (expressed as the entrained VSLS fractions) determine the total amount of VSLS entrained above the $17 \mathrm{~km}$ surface (colored lines in Fig. 3a and b). The hot spot emissions during the second part of the cruise result in strongest VSLS entrainment although the vertical transport intensity is larger during the first part of the cruise. If events of strong vertical transport would coincide with strong VSLS emissions, one could expect very large amounts of VSLS being transported into the stratosphere. However, strong localized oceanic sources related to coastal regions determine the peak emissions and therefore no direct link between emission strength and wind variations or vertical transport intensity exists. For both bromocarbons the total entrainment is highly correlated with the surface emissions $(r>0.95)$ but not correlated with the transport efficiency.

The contribution of VSLS to the stratospheric bromine loading depends on SGI as discussed above and also on PGI where inorganic bromine resulting from the degradation of $\mathrm{CHBr}_{3}$ and $\mathrm{CH}_{2} \mathrm{Br}_{2}$ is entrained into the stratosphere. Similar to what has been done for the VSLS source gases the $\mathrm{Br}_{\mathrm{y}}$ entrainment above the cold point has been estimated for $\mathrm{Br}_{\mathrm{y}}$ with wet deposition calculated as described in Sect. 2.3. For local West Pacific emissions considerably more $\mathrm{Br}_{\mathrm{y}}$ originating from the degradation of $\mathrm{CHBr}_{3}$ than from the degradation of $\mathrm{CH}_{2} \mathrm{Br}_{2}$ is entrained into the stratosphere (Fig. 3c). This is due to stronger $\mathrm{CHBr}_{3}$ fluxes and the fact that $\mathrm{CHBr}_{3}$ contains one more bromine atom than $\mathrm{CH}_{2} \mathrm{Br}_{2}$. Additionally, for $\mathrm{CH}_{2} \mathrm{Br}_{2}$ a larger fraction is entrained already as source gas and therefore less bromine is left for potential PGI. Maximum amounts of product gases are transported into the stratosphere for peak emission events similar to what has been noted for the SGI. Overall SGI and PGI of bromocarbons emitted in the West Pacific are determined by the intensity of surface emissions and show the same strong variability. This holds for a region of intense vertical transport where transport efficiency shows less variability than the seato-air flux.

On average more bromine source gas particles are entrained than product gas particles. The ratio of SGI and PGI for $\mathrm{CHBr}_{3}$ is 3.4 on average and shows some variability over 
all emission events ranging from 2 to 6 . Note that the given average value (3.4) is calculated from the mean of the time series shown in Fig. 3 and can also be derived from Fig. 4. While $\mathrm{CHBr}_{3}$ contributes 3.4 times more $\mathrm{Br}_{\mathrm{y}}$ by SGI than by PGI the ratio is even larger for $\mathrm{CH}_{2} \mathrm{Br}_{2}$ where 18 times more $\mathrm{Br}_{\mathrm{y}}$ results from SGI compared to PGI. This relatively large importance of SGI compared to PGI derived for West Pacific emissions depends strongly on the modeled wet deposition of $\mathrm{Br}_{\mathrm{y}}$ and relies on the accurate representation of precipitation within FLEXPART as well as on the accurate representation of bromine chemistry (including heterogeneous reactions) within p-TOMCAT. If $\mathrm{Br}_{\mathrm{y}}$ is assumed to be insoluble the amount of PGI entrained above $17 \mathrm{~km}$ is considerable larger with $\mathrm{CHBr}_{3}\left(\mathrm{CH}_{2} \mathrm{Br}_{2}\right)$ SGI contributing only 0.7 (0.8) times the $\mathrm{Br}_{\mathrm{y}}$ compared to PGI (Fig. 4). While the overall amount of $\mathrm{Br}_{\mathrm{y}}$ entrained is different, the variability of PGI from insoluble $\mathrm{Br}_{\mathrm{y}}$ along the cruise track (not shown here) is very similar to the variability of PGI from soluble $\mathrm{Br}_{\mathrm{y}}$ (Fig. 3c).

In order to determine the potential impact of $\mathrm{CHBr}_{3}$ and $\mathrm{CH}_{2} \mathrm{Br}_{2}$ on stratospheric ozone their ODPs have been estimated with a methodology specifically developed for localised emissions. The ODPs (Fig. 3d) are considerably larger than estimates obtained from previous global model studies (Brioude et al., 2010; Wuebbles et al., 2011). While in these studies mean ODP values were obtained as averages over longer time periods and large regions, we present the first pointwise ODPs calculated individually for emission measurements. By definition, ODPs are a function of chemical and transport properties relevant for the VSLS but do not take into account the strength of the emission. As a result the relative ozone-destroying capabilities for VSLS (expressed as ODPs) can be large when transport from the boundary into the stratosphere is efficient while the actual contribution of VSLS to the stratospheric $\mathrm{Br}_{\mathrm{y}}$ loading is small due to weak VSLS emissions.

Calculated ODPs depend critically on the representation of tropospheric transport resulting in ODP peaks for time periods where a large fraction of VSLS are transported into the stratosphere (Fig. 3a, b, and d; Figs. 1 and 4 in Pisso et al., 2010) and hence are sensitive to the convective parameterization. In general our estimated ODPs show a large variability where episodic injections estimated for a highly convective region can be orders of magnitude higher than the global mean. We find maximum ODP values of 6.4 (4.1) for $\mathrm{CHBr}_{3}\left(\mathrm{CH}_{2} \mathrm{Br}_{2}\right)$ implying that under specific meteorological conditions one unit of $\mathrm{CHBr}_{3}$ emitted from the ocean surface can destroy 6.4 times the amount of ozone depleted by one unit of CFC-11. However, cases of maximum ODP (or maximum vertical transport) do not necessarily coincide with peak emissions of VSLS. Our results indicate that mean ODP values for VSLS obtained by coarse global models mask a large variance over space and time. This can lead to an inaccurate estimation of the VSLS contribution to stratospheric ozone depletion.

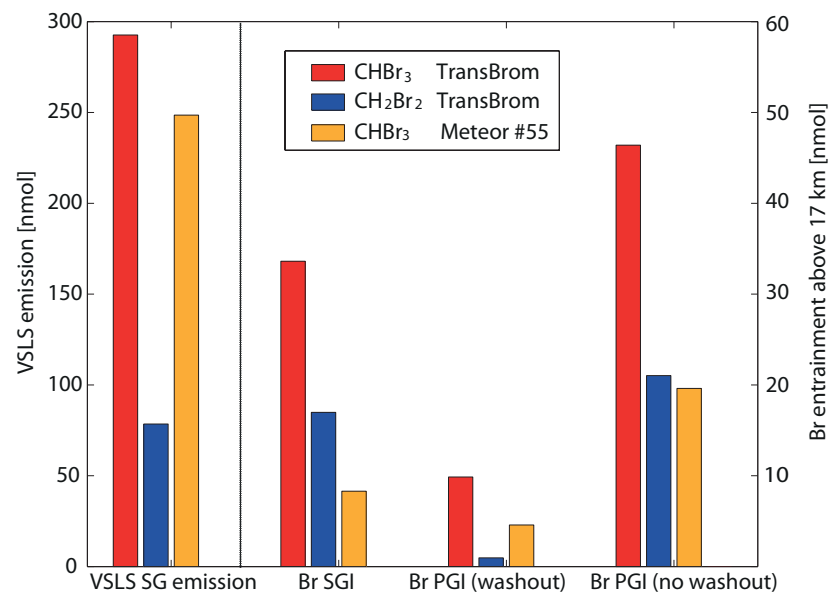

Fig. 4. Average $\mathrm{SG}$ emissions of $\mathrm{CHBr}_{3}$ and $\mathrm{CH}_{2} \mathrm{Br}_{2}$ observed in the West Pacific during the TransBrom Sonne campaign and in the tropical Atlantic during the Meteor \#55 campaign are shown (left side). Estimates of bromine SGI, bromine PGI in case of $\mathrm{Br}_{\mathrm{y}}$ washout and bromine PGI in case of no $\mathrm{Br}_{\mathrm{y}}$ washout have been derived based on the emissions and are also displayed (right side).

\subsection{Comparison with SGI and PGI based on tropical Atlantic emissions}

It is of interest to compare VSLS emissions and their subsequent atmospheric transport for different oceanic regions. Therefore observations of VSLS emissions during the R/V Meteor cruise \#55 in the tropical Atlantic in October/November 2002 (Quack et al., 2004) are used to calculate SGI and PGI for $\mathrm{CHBr}_{3}$. Figure 4 shows mean emissions of $\mathrm{CHBr}_{3}$ observed during the Meteor \#55 and Sonne TransBrom cruises. Emissions during both campaigns are on average of very similar magnitude and in the middle range of global mean emission estimates. The sea-to-air flux observed during the Meteor \#55 cruise is strongly localized (Quack et al., 2004) as it is also the case for TransBrom, and includes intense emissions in tropical open ocean regions. Additionally, mean $\mathrm{CH}_{2} \mathrm{Br}_{2}$ emissions for the Sonne TransBrom cruise are displayed which are quite low compared to global mean estimates and compared to $\mathrm{CHBr}_{3}$ emissions during the same cruise. Note that $\mathrm{CH}_{2} \mathrm{Br}_{2}$ sea-to-air fluxes were not measured during the Meteor \#55 cruise.

For both campaigns mean SGI and PGI values, where the latter one is estimated for soluble and insoluble $\mathrm{Br}_{y}$, are shown in Fig. 4. SGI estimated for $\mathrm{CHBr}_{3}$ emissions in the tropical Atlantic is relatively low with $1.1 \%$ of all emitted SG being transported into the tropical stratosphere while in the West Pacific $3.8 \%$ of all emitted SG are entrained. (Note that one unit of SG emissions of $\mathrm{CHBr}_{3}\left(\mathrm{CH}_{2} \mathrm{Br}_{2}\right)$ contains three (two) times the amount of bromine compared to one unit of SGI or PGI entrainment.) The difference results from stronger convective activity in the West Pacific which acts as the main mechanism for the fast vertical uplift of air masses. 
a) TransBrom $\mathrm{CHBr}_{3}$ (SGI)

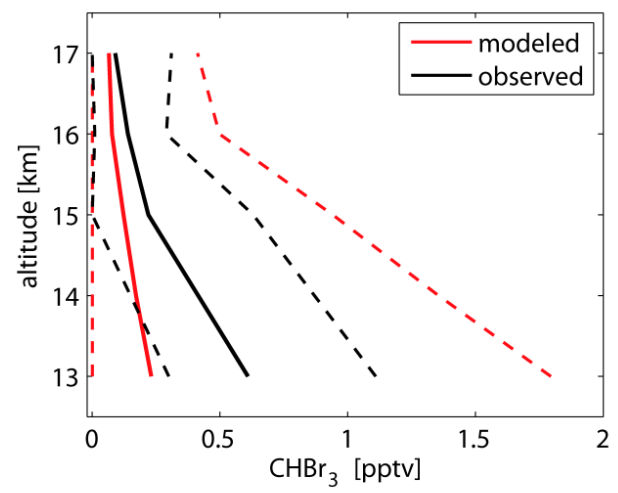

c) Meteor55 $\mathrm{CHBr}_{3}$ (SGI)

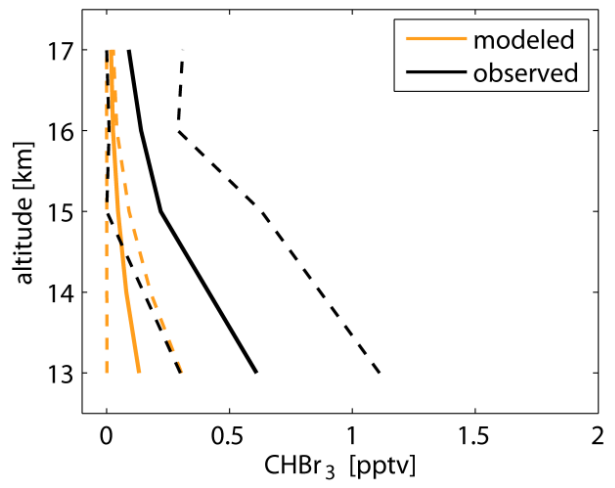

b) TransBrom $\mathrm{CH}_{2} \mathrm{Br}_{2}$ (SGI)

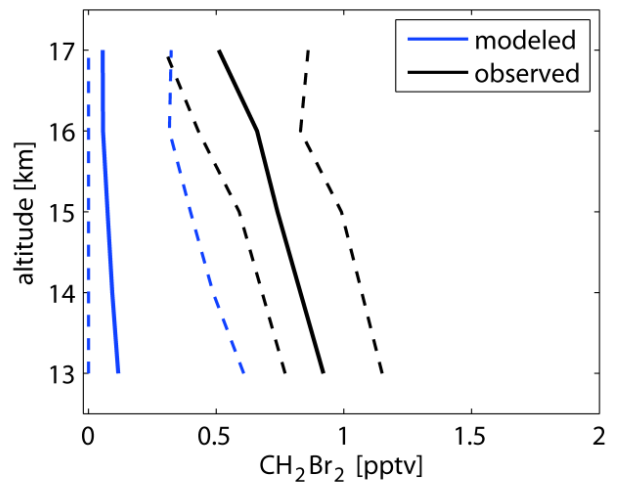

d) TransBrom $\mathrm{Br}(\mathrm{SGI}+\mathrm{PGI})$

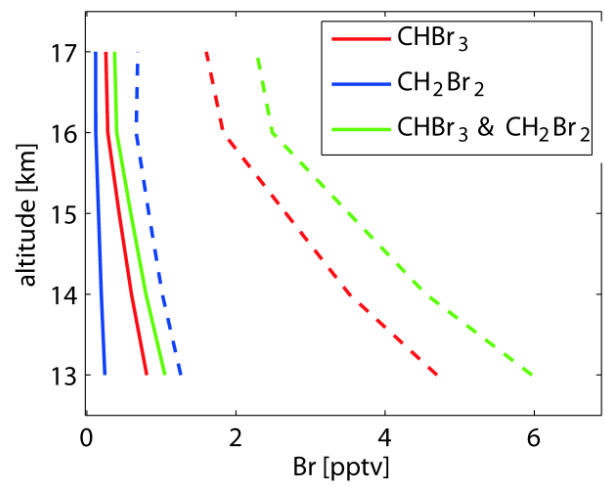

Fig. 5. VSLS profiles based on atmospheric observations (black lines) and estimated from observed emissions (colored lines) of West Pacific $\mathrm{CHBr}_{3}$ (a), West Pacific $\mathrm{CH}_{2} \mathrm{Br}_{2}$ (b), and tropical Atlantic $\mathrm{CHBr}_{3}$ (c) are shown. Also total Br profiles (PG and SG) based on West Pacific $\mathrm{CHBr}_{3}$ and $\mathrm{CH}_{2} \mathrm{Br}_{2}$ emissions are displayed (d). For all profiles lower and upper limits (dashed lines) and mean values (solid lines) are given.

For PGI estimated for soluble $\mathrm{Br}_{\mathrm{y}}$ similar results are found with stronger entrainment for West Pacific emissions compared to tropical Atlantic emissions. However, for PGI the difference is less pronounced than for SGI indicating that although variability of vertical transport leads to a more efficient SGI and PGI in the West Pacific in the first place, the variability of wet deposition acts to reduce this difference and decreases the PGI more in the West Pacific than in the tropical Atlantic. Overall, the main difference between $\mathrm{CHBr}_{3}$ entrainment in the West Pacific and in the tropical Atlantic results from differences in the efficiency of the vertical transport from the boundary layer in the emission region into the stratosphere. However, variability of PGI and SGI within one campaign comes mainly from the variability of the emission strength and only in the second place from the variability of the vertical transport.

For $\mathrm{CH}_{2} \mathrm{Br}_{2}$ SGI is quite efficient and more than $10 \%$ of the emitted $\mathrm{SG}$ are injected into the stratosphere. However, $\mathrm{CH}_{2} \mathrm{Br}_{2}$ PGI for soluble $\mathrm{Br}_{\mathrm{y}}$ is very low as already discussed for the time series displayed in Fig. 3. In case $\mathrm{Br}_{\mathrm{y}}$ is modeled as an insoluble tracer the PGI from $\mathrm{CHBr}_{3}\left(\mathrm{CH}_{2} \mathrm{Br}_{2}\right)$ is 5 (20) times larger than PGI of soluble $\mathrm{Br}_{\mathrm{y}}$. Estimates based on insoluble $\mathrm{Br}_{\mathrm{y}}$ can be considered an upper boundary of PG entrainment resulting from emissions observed at the ocean surface. The large differences to the estimates based on soluble $\mathrm{Br}_{\mathrm{y}}$ reflect an efficient washout process in our simulations. Our findings are in contrast to recent results from Aschmann et al. (2011) who, using a limited model domain between 10 and $55 \mathrm{~km}$ altitude, found that inorganic bromine originating from convective outflow can enter the stratosphere without being effected much by wet deposition. Note that Aschmann et al. (2011), in contrast to our study, use a detailed treatment of heterogeneous reactions and sedimentation processes above $10 \mathrm{~km}$ but do not take into account wet deposition in the troposphere below $10 \mathrm{~km}$ which turns out to be a very efficient wash-out process in our simulations.

\subsection{PG and SG profiles}

Based on observed VSLS emissions in the West Pacific and tropical Atlantic and subsequent modeling of atmospheric transport we estimate VSLS vertical profiles in the TTL. In Fig. 5 our estimates based on localized emission measurements (hereinafter referred to as emission-based 
estimates) are compared to atmospheric VSLS profiles based on globally available upper-air measurements (Montzka and Reimann et al., 2011). This comparison provides a new aspect to the current state of VSLS modeling where an agreement between upper-air measurements and model results is obtained by adjusting oceanic emission scenarios instead of using the emission rates as an independent source of information. The emission-based atmospheric VSLS profiles depend on the accurate representation of vertical transport within the model simulation. The profiles are estimated based on the before presented transport calculations of emitted VSLS abundances and do not take into account mixing with air masses from other regions. As a result the emission-based profiles are representative for atmospheric abundances based on observed emissions along two cruise tracks in the tropical Atlantic and West Pacific.

Available VSLS upper-air observations originate from several tropical aircraft and balloon campaigns and were averaged to obtain the measurement-based atmospheric VSLS profiles (Montzka and Reimann et al., 2011). Data from aircraft observations during PEM-West A and B, TC4, PreAVE, and CR-AVE aircraft campaigns (Schauffler et al., 1999; Aschmann et al., 2009; Hossaini et al., 2010; Liang et al., 2010; Salawitch et al., 2010; Ashfold et al., 2012) and from Teresina balloon observations (Laube et al., 2008; Brinckmann et al., 2012) are included in the atmospheric VSLS profiles. The observations are representative for time and location of the flight tracks used for the aircraft and balloon campaigns (see Liang et al., 2010 for details), which do not coincide with time and location of the TransBrom Sonne campaign in the tropical West Pacific during autumn 2009. As a result the emission-based and measurement-based profiles are not coincident in time and space and can therefore only be compared in a qualitative way. While we do not expect excellent agreement as one would for modeling atmospheric transport for combined ship and aircraft campaigns we can compare mean, minimum and maximum values to determine which role emissions and transport of VSLS in the tropical West Pacific play compared to upper-air estimates from other regions with different emission and transport properties.

For $\mathrm{CHBr}_{3}$ emission-based estimates and observations show a good agreement (Fig. 5a). The fact that the relative fraction of upper-air $\mathrm{CHBr}_{3}$ resulting from West Pacific emission and transport properties is in good agreement with measurement-based global profiles is consistent with the West Pacific emissions being in the middle range of global emission estimates. The mean profiles are of similar magnitude above $15 \mathrm{~km}$ with observations being slightly larger. The maximum $\mathrm{CHBr}_{3}$ abundances derived from observations $(0.31 \mathrm{ppt}$ at $17 \mathrm{~km})$ are slightly smaller than the ones derived from the emission-based estimates $(0.36 \mathrm{ppt}$ at $17 \mathrm{~km})$ indicating that localized strong sources found at the ocean surface can lead to higher mixing ratios in the upper atmosphere than observed so far. On average $\mathrm{CHBr}_{3}$ emitted in the West

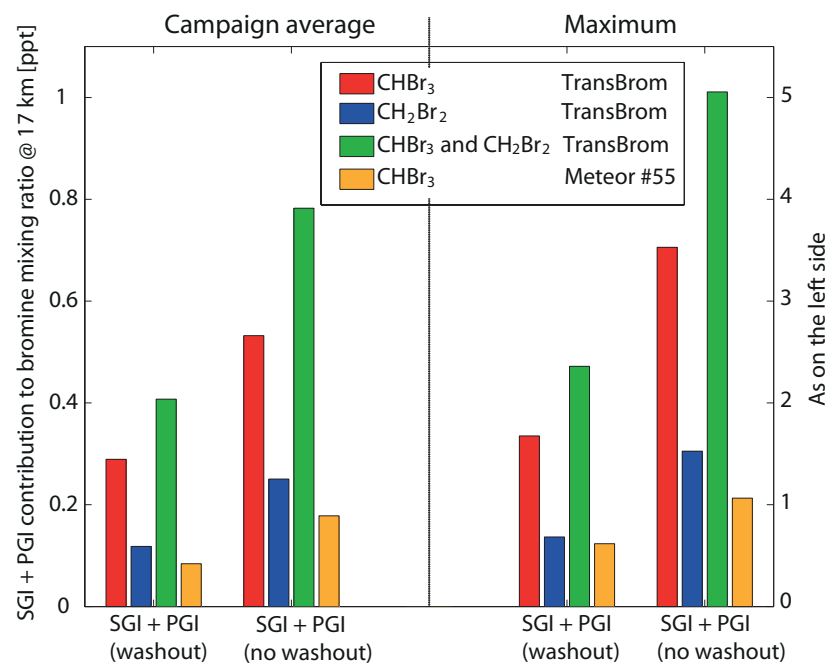

Fig. 6. Modeled stratospheric $\mathrm{Br}$ mixing ratios (ppt) at $17 \mathrm{kmfrom}$ SGI and PGI contributions based on West Pacific (TransBrom) $\mathrm{CHBr}_{3}, \mathrm{CH}_{2} \mathrm{Br}_{2}$ and tropical Atlantic (Meteor\#55) $\mathrm{CHBr}_{3}$ emissions. Results are given in form of the campaign average values (left side) and in form of maximum values found for peak emission events (right side), taking washout and no wash-out simulations into account (see also Fig. 4).

Pacific as observed during the cruise can lead to atmospheric abundances of 0.08 ppt $\mathrm{CHBr}_{3}$ at $17 \mathrm{~km}$ if not mixed with other air masses. This is smaller than global estimates derived from modeling studies which range between $0.1 \mathrm{ppt}$ and 0.15 ppt (Warwick et al., 2006; Aschmann et al., 2009; Hossaini et al., 2010). For $\mathrm{CH}_{2} \mathrm{Br}_{2}$, the emission-based estimates are much smaller than the atmospheric observations (Fig. 5b). This difference is consistent with the low emissions observed in the West Pacific open ocean during TransBrom compared to global emission estimates, indicating that emissions from other oceanic regions are more important for the stratospheric budget. Also shown are $\mathrm{CHBr}_{3}$ estimates based on emissions in the tropical Atlantic observed during the Meteor \#55 campaign (Fig. 5c). As opposed to the West Pacific estimates the modeled $\mathrm{CHBr}_{3}$ abundances are considerably smaller than the observed ones. The modeled $\mathrm{CHBr}_{3}$ drops down to zero above $15 \mathrm{~km}$ indicating that there is only very little convectively driven transport reaching the upper TTL on short timescales. As a result the tropical Atlantic during the Meteor cruise \#55 did not serve as an important source region for stratospheric VSLS although VSLS emissions were similar to the ones observed in the West Pacific.

Figure 5d shows total $\mathrm{Br}$ profiles from SGI and PGI based on localized emission-measurements from TransBrom for the scenario of soluble $\mathrm{Br}_{\mathrm{y}}$. The average estimates of total $\mathrm{Br}$ at $17 \mathrm{~km}$ amount to $0.29 \mathrm{ppt}$ for $\mathrm{CHBr}_{3}$ with only $20 \%$ from PGI and 0.12 ppt for $\mathrm{CH}_{2} \mathrm{Br}_{2}$ with less than $10 \%$ from PGI. Together both VSLS from the West Pacific region observed along the cruise track provide a relative contribution to the 
stratospheric bromine of about $0.41 \mathrm{ppt}$ on average assuming soluble $\mathrm{Br}_{\mathrm{y}}$. The major fraction of total $\mathrm{Br}$ results from $\mathrm{CHBr}_{3}$ and its degradation products and only a small part originates from $\mathrm{CH}_{2} \mathrm{Br}_{2}$. This relatively low importance of $\mathrm{CH}_{2} \mathrm{Br}_{2}$ is caused by the low emissions observed in the West Pacific in October 2009 and are expected to be quite different for other oceanic regions based on upper-air observations of $\mathrm{CH}_{2} \mathrm{Br}_{2}$ (Salawitch et al., 2010). Globally the contribution of $\mathrm{CH}_{2} \mathrm{Br}_{2}$ to stratospheric bromine is expected to be of equal or greater importance compared to $\mathrm{CHBr}_{3}$ (e.g., Liang et al., 2010; Aschmann et al., 2011).

Figure 6 provides a detailed comparison of the $\mathrm{Br}$ mixing ratios at $17 \mathrm{~km}$ for the two scenarios assuming washout and no washout. First we want to address the TransBrom campaign average (left side). If $\mathrm{Br}_{\mathrm{y}}$ would have no sink from wet deposition than the $\mathrm{Br}$ estimate would amount to $0.53 \mathrm{ppt}$ for $\mathrm{CHBr}_{3}$ and to $0.25 \mathrm{ppt}$ for $\mathrm{CH}_{2} \mathrm{Br}_{2}$. Together the two organic bromocarbons from the West Pacific region observed during the cruise would contribute about $0.78 \mathrm{ppt} \mathrm{Br}$ to the stratosphere. For both scenarios (washout with $0.41 \mathrm{ppt}$ and no washout with $0.78 \mathrm{ppt}$ ) the contribution of the two VSLS to the stratospheric bromine loading is rather small compared to results from other studies (e.g., $5 \mathrm{ppt}$ from Liang et al. (2010), $2.6 \mathrm{ppt}$ from Hossaini et al. (2010) for a 10 day $\mathrm{Br}_{\mathrm{y}}$ lifetime, $4.4 \mathrm{ppt}-5 \mathrm{ppt}$ from Aschmann et al. (2011) depending on the applied dehydration scheme, $2 \mathrm{ppt}$ from Brinckmann et al. (2012)). Our relatively low estimate of the VSLS contributions from the West Pacific region can very likely be attributed to a large part to the low $\mathrm{CH}_{2} \mathrm{Br}_{2}$ emissions observed during the cruise resulting in a very low $\mathrm{CH}_{2} \mathrm{Br}_{2}$ contribution to stratospheric $\mathrm{Br}_{\mathrm{y}}(0.12 \mathrm{ppt}-0.25 \mathrm{ppt}$ depending on the washout treatment). Our estimates of the $\mathrm{CHBr}_{3}$ contribution ( $0.29 \mathrm{ppt}$ to $\left.0.53 \mathrm{ppt}\right)$ is also on the lower side when compared to global estimates from previous studies which range around 1 ppt (e.g., Dvortsov et al., 1999; Nielsen and Douglass, 2001; Sinnhuber and Folkins, 2005) but agrees notably better than $\mathrm{CH}_{2} \mathrm{Br}_{2}$. For localized maximum emissions observed close to coastal regions during TransBrom (right side of Fig. 6) one can expect mixing ratios of $2.4 \mathrm{ppt}$ (5.1 ppt) assuming washout (no washout) of the product gases based on a contribution of $1.6 \mathrm{ppt}$ (3.5 ppt) from $\mathrm{CHBr}_{3}$ and $0.7 \mathrm{ppt}(1.5 \mathrm{ppt})$ from $\mathrm{CH}_{2} \mathrm{Br}_{2}$. The upper boundary estimates for the no washout scenario are roughly consistent with a study from Salawitch et al. (2005) which suggest that the contribution of PGI to stratospheric bromine could be as high as 5-7 ppt if no washout occurs above the level of main convective outflow. $\mathrm{CHBr}_{3}$ emissions observed in the tropical Atlantic during the Meteor \#55 campaign result in a low overall contribution (SGI+PGI) to stratospheric $\mathrm{Br}$ irrespective of the treatment of VSLS wet deposition amounting to $0.08 \mathrm{ppt}$ (washout) or $0.18 \mathrm{ppt}$ (no washout).

Figure 7 illustrates how much bromine product gases escape the washout process and are entrained into the TTL and into the stratosphere based on our modeling results. From all air parcels which encounter fast uplift by convection the fraction of bromine which has been activated from SG to PG is determined based on the scenario of insoluble $\mathrm{Br}_{\mathrm{y}}$. From the amount of activated $\mathrm{Br}$ the fraction which has not been washed out is determined based on the scenario where $\mathrm{Br}_{\mathrm{y}}$ is assumed to be soluble. For air masses entrained between 12 and $14 \mathrm{~km}$ by deep convection $40 \%$ of all bromine is available in the form of PG at the moment of their detrainment from convection. However, only a fraction $(35 \%)$ of these PG are still present while the rest $(65 \%)$ has been washed out during transport from the surface into the TTL. When the same air masses at a later point are entrained into the stratosphere (above $17 \mathrm{~km}$ ) the amount of PG is now larger $(75 \%)$. From this PG abundance $14 \%$ are still present while the rest $(86 \%)$ is lost due to wash out during transport from the surface into the TTL and through the TTL into the stratosphere.

Results imply that when air enters the TTL $(12-16 \mathrm{~km})$ about $65-71 \%$ of all up to this moment available PG have been washed out. More efficient washout but less PG activation can be seen for air parcels which are detrained between 12 and $14 \mathrm{~km}$ (with the level of main convective outflow at $12 \mathrm{~km}$ ) compared to air parcels detrained at higher altitudes between 14 and $16 \mathrm{~km}$. Air parcels which have been uplifted into the 10-12 km layer just below the TTL show similar levels of activation and wash out. Overall air masses which enter the TTL by fast convection have experienced efficient washout and lost around 26-32\% of their original total bromine loading (corresponding to $65-71 \%$ washed out bromine of $40-45 \%$ activated PG). This is in agreement with results from Liang et al. (2010) who find wet scavenging to remove about $30 \%$ of all bromine mostly during large scale precipitation.

The evaluation of the same air masses once they reached the cold point at around $17 \mathrm{~km}$ shows that although more $\mathrm{Br}$ is activated after transport through the TTL a smaller fraction of the activated $\mathrm{Br}$ remains unaffected by wash out. This implies further efficient washout of inorganic bromine during TTL transport. A detailed analysis of our simulation shows that air masses originally entrained by deep convection between $14-16 \mathrm{~km}$ have at $17 \mathrm{~km}$ higher PG activation then before (62\% versus $45 \%$ ) while the fraction of $\mathrm{Br}$ remaining unaffected by washout changes only slightly ( $25 \%$ versus $29 \%$ ). However, air masses which originated from convection detraining between 12 and $14 \mathrm{~km}$ show considerable higher PG activation ( $75 \%$ versus $40 \%)$ and considerable less $\mathrm{Br}$ unaffected by washout (14\% versus $35 \%$ ) then before. As a consequence the level of convective outflow has a significant impact on the efficiency of $\mathrm{Br}_{\mathrm{y}}$ removal by wet deposition as well as on the overall contribution to stratospheric bromine. Considering all air parcels which reach $17 \mathrm{~km}$ air masses which are transported into the upper TTL above $14 \mathrm{~km}$ by deep convection will contribute $54 \%$ (38\% $\mathrm{SG}+0.62 .25 \% \mathrm{PG})$ of their original bromine loading obtained from oceanic VSLS emissions while air masses detrained by convection below 14 (12) km contribute 36 (30) \%. 


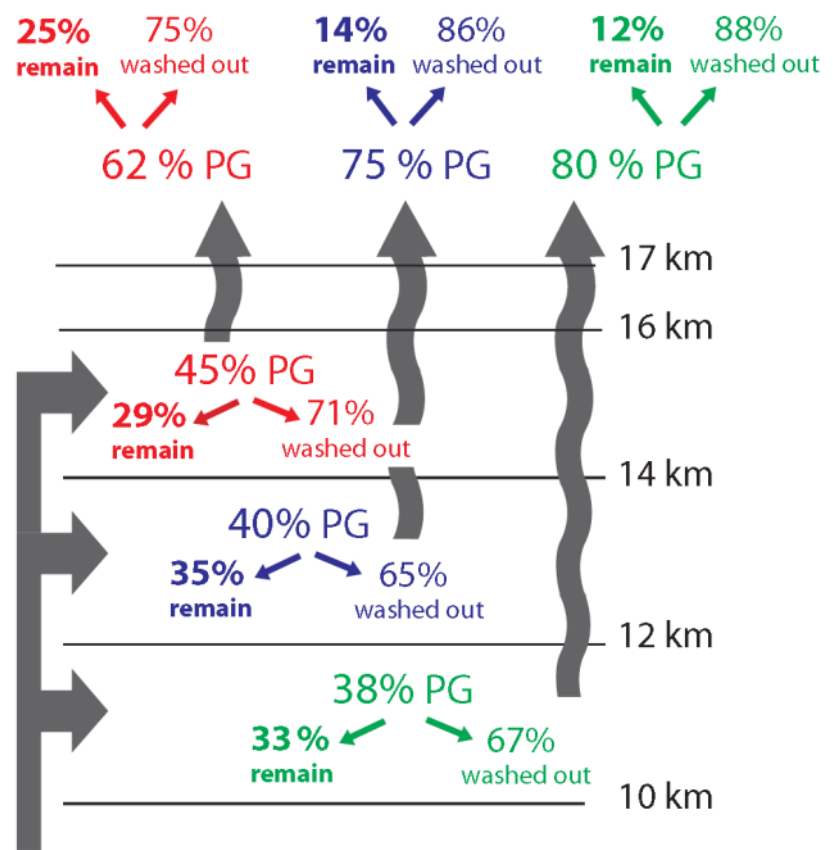

Fig. 7. For all air masses which encounter fast uplift by convection PG at the moment of detrainment from convection is given relative to the total amount of bromine originally contained in the air mass. Based on the amount of PG the fraction of effectively remaining PG (not washed out) and the fraction of lost PG (washed out) are given for air masses entrained between 10 and $12 \mathrm{~km}$ (green), 12 and $14 \mathrm{~km}$ (blue), and 14 and $16 \mathrm{~km}$ (red). Also displayed in the upper part of the figure are the same quantities at the moment of entrainment above $17 \mathrm{~km}$.

\section{Conclusions}

We present results from a modeling study which estimates upper-air VSLS abundances based on observations of localized oceanic emissions. Since our calculations use on in-situ observations along cruise tracks the modeled VSLS entrainment is not a representative global estimate but rather a measure on how emission and transport in the cruise track regions will contribute to global VSLS estimates. Our study focuses on the West Pacific VSLS contributions which are expected to be important for global VSLS estimates since this area represents the most important transport pathway into the stratosphere (e.g., Gettelman et al., 2002; Liu and Zipser, 2005). The $\mathrm{CHBr}_{3}$ and $\mathrm{CH}_{2} \mathrm{Br}_{2}$ emissions from the West Pacific used in this study include measurements from open ocean and coastal regions and are among the first VSLS observations obtained in this area. Additionally, $\mathrm{CHBr}_{3}$ contributions from the tropical Atlantic are estimated based on oceanic emissions which are comparable to the ones observed in the West Pacific.

SGI and PGI estimated from local sea-to-air flux observations are characterized by a large variability where episodic injections can be orders of magnitude higher than the global mean. Our results indicate that mean values of VSLS SGI and PGI obtained by coarse global models mask a large variance over space and time. This can lead to an inaccurate estimation of the VSLS contribution to stratospheric ozone depletion. Especially if the intensity of vertical transport and the VSLS sea-to air flux are correlated, coarse models could potentially over- or underestimate upper-air VSLS abundances. Such a correlation has not been observed for above presented emission and transport in the West Pacific since for both bromocarbons, the peak emissions have been determined by strong localized oceanic sources which are not related to atmospheric transport characteristics. However, in a scenario of relatively uniform oceanic concentrations the emission rates could be determined by the wind speed variations which would enable a correlation between emission strength and vertical transport intensity. Such a scenario seems conceivable in other oceanic regions and also for VSLS with different emission characteristics, such as $\mathrm{CH}_{3} \mathrm{I}$, and will be addressed in a follow-up study.

$\mathrm{CHBr}_{3}$ and $\mathrm{CH}_{2} \mathrm{Br}_{2}$ emitted in the West Pacific, a region of intense vertical transport, have a large potential to destroy stratospheric ozone as illustrated by their high ODP values. Where and when strong vertical transport and strong emissions coincide, large VSLS entrainment into the stratosphere can be expected. For $\mathrm{CHBr}_{3}$ mean emission-based estimates are consistent with upper-air observations while localized peak emissions lead to larger than so far observed atmospheric abundances. For $\mathrm{CH}_{2} \mathrm{Br}_{2}$, emission in the West Pacific and thereupon estimated atmospheric abundances are considerably lower than global observations. Both bromocarbons will contribute directly and in form of their product gases to the stratospheric bromine loading. Current observational estimates of the total contribution of all VSLS to the stratospheric bromine budget are around $5 \mathrm{pptv}$. We estimate for $\mathrm{CHBr}_{3}$ and $\mathrm{CH}_{2} \mathrm{Br}_{2}$ from the West Pacific to provide a relative source gas contribution to the stratospheric bromine loading of 0.3 pptv $\mathrm{Br}$ on average and $1.7 \mathrm{pptv} \mathrm{Br}$ in a maximum case. Together with product gas contributions, this results in a total $\mathrm{Br}$ entrainment of 0.4 pptv based on West Pacific average emissions and 2.3 pptv for cases of maximum emissions. $\mathrm{CHBr}_{3}$ emissions obtained during a ship cruise in the tropical Atlantic are similar to the ones observed in the West Pacific. However, due to the lack of high-reaching convection, $\mathrm{CHBr}_{3}$ from the tropical Atlantic contributes little to the global bromine budget with $0.06 \mathrm{pptv} \mathrm{Br}$ from source gas injection and $0.02 \mathrm{pptv} \mathrm{Br}$ from product gas injection.

Our results show that bottom-up emission-based VSLS estimates as derived for two ship cruises lead to only relatively small or at best moderate atmospheric VSLS abundances when compared with upper-air measurements. While emissions from the tropical West Pacific were expected to be of importance for the global VSLS budget our estimates imply only a moderate contribution from this region. Our results indicate a gap between bottom-up estimates based on ship campaign observations and top-down estimates derived 
from modeling studies reproducing background atmospheric concentrations and illustrate the need to further quantify the spatial and temporal highly variable VSLS emission rates.

Acknowledgements. We thank the TransBrom Sonne team for collecting the VSLS measurements. The authors are grateful to the ECMWF for making the reanalysis product ERA-Interim available. This study is carried out within the WGL-project TransBrom (www.geomar.de/ transbrom); the ship campaign on RV SONNE was financed by the BMBF through grant 03G0731A. This work also contributes to the EU project SHIVA (grant no. 226224).

The service charges for this open access publication have been covered by a Research Centre of the Helmholtz Association.

Edited by: W. T. Sturges

\section{References}

Abbatt, J. P. D.: Interactions of Atmospheric Trace Gases with Ice Surfaces: Adsorption and Reaction, Chem. Rev., 103, 47834800, 2003.

Aschmann, J., Sinnhuber, B.-M., Atlas, E. L., and Schauffler, S. M.: Modeling the transport of very short-lived substances into the tropical upper troposphere and lower stratosphere, Atmos. Chem. Phys., 9, 9237-9247, doi:10.5194/acp-9-9237-2009, 2009.

Aschmann, J., Sinnhuber, B.-M., Chipperfield, M. P., and Hossaini, R.: Impact of deep convection and dehydration on bromine loading in the upper troposphere and lower stratosphere, Atmos. Chem. Phys., 11, 2671-2687, doi:10.5194/acp-11-26712011, 2011.

Ashfold, M. J., Harris, N. R. P., Atlas, E. L., Manning, A. J., and Pyle, J. A.: Transport of short-lived species into the Tropical Tropopause Layer, Atmos. Chem. Phys., 12, 6309-6322, doi:10.5194/acp-12-6309-2012, 2012.

Brinckmann, S., Engel, A., Bönisch, H., Quack, B., and Atlas, E.: Short-lived brominated hydrocarbons - observations in the source regions and the tropical tropopause layer, Atmos. Chem. Phys., 12, 1213-1228, doi:10.5194/acp-12-1213-2012, 2012.

Brioude, J., Portmann, R. W., Daniel, J. S., Cooper, O. R., Frost, G. J., Rosenlof, K. H., Granier, C., Ravishankara, A. R., Montzka, S. A. and Stohl, A.: Variations in ozone depletion potentials of very short-lived substances with season and emission region, Geophys. Res. Lett. 37, L19804, doi:10.1029/2010GL044856, 2010.

Butler, J. H., King, D. B., Lobert, J. M., Montzka, S. A., YvonLewis, S. A., Hall, B. D., Warwick, N. J., Mondeel, D. J., Aydin, M., and Elkins, J. W.: Oceanic distributions and emissions of short-lived halocarbons, Global Biogeochem. Cy., 21, GB1023, doi:10.1029/2006GB002732, 2007.

Carpenter, L. J. and Liss, P. S.: On temperate sources of Bromoform and other reactive organic bromine gases, J. Geophys. Res. 105, 20539-20547, 2000.

Dee, D. P., Uppala, S. M., Simmons, A. J., Berrisford, P., Poli, P., Kobayashi, S., Andrae, U., Balmaseda, M. A., Balsamo, G., Bauer, P., Bechtold, P., Beljaars, A. C. M., van de Berg, L., Bidlot, J., Bormann, N., Delsol, C., Dragani, R., Fuentes, M., Geer,
A. J., Haimberger, L., Healy, S. B., Hersbach, H., Hólm, E. V., Isaksen, L., Kållberg, P., Köhler, M., Matricardi, M., McNally, A. P., Monge-Sanz, B. M., Morcrette, J.-J., Park, B.-K., Peubey, C., de Rosnay, P., Tavolato, C., Thépaut, J.-N., and Vitart, F.: The ERA-Interim reanalysis: configuration and performance of the data assimilation system, Q. J. Roy. Meteorol. Soc., 137, 553597, 2011.

Dorf, M., Butz, A., Camy-Peyret, C., Chipperfield, M. P., Kritten, L., and Pfeilsticker, K.: Bromine in the tropical troposphere and stratosphere as derived from balloon-borne $\mathrm{BrO}$ observations, Atmos. Chem. Phys., 8, 7265-7271, doi:10.5194/acp-8-72652008, 2008.

Dvortsov, V. L., Geller, M. A., Solomon, S., Schauffler, S. M., Atlas, E. L., and Blake, D. R.: Rethinking reactive halogen budgets in the midlatitude lower stratosphere, Geophys. Res. Lett., 26, 1699-1702, 1999.

Forster, C., Cooper, O., Stohl, A., Eckhardt, S., James, P., Dunlea, E., Nicks D. K., Holloway, Jr. J. S., Hübler, G., Parrish, D. D., Ryerson, T. B., and Trainer, M.: Lagrangian transport model forecasts and a transport climatology for the Intercontinental Transport and Chemical Transformation 2002 (ITCT 2k2) measurement campaign, J. Geophys. Res., 109, D07S92, doi:10.1029/2003JD003589, 2004.

Forster, C., Stohl, A., and Seibert, S.: Parameterization of Convective Transport in a Lagrangian Particle Dispersion Model and Its Evaluation, J. Appl. Meteor. Climatol., 46, 403-422, 2007.

Forster, C., Wandinger, U., Wotawa, G., James, P., Mattis, I., Althausen, D., Simmonds, P., O’Doherty, S., Kleefeld, C., Jennings, S. G., Schneider, J., Trickl, T., Kreipl, S., Jäger, H., and Stohl, A.: Transport of boreal forest fire emissions from Canada to Europe, J. Geophys. Res., 106, 22887-22906, 2001.

Frenzel, A., Scheer, V., Sikorski, R., George, C., Behnke, W. and Zetzsch, C.: Heterogeneous Interconversion Reactions of $\mathrm{BrNO}_{2}, \mathrm{ClNO}_{2}, \mathrm{Br}_{2}$ and $\mathrm{Cl}_{2}$, J. Phys. Chem. A., 102, 13291337, 1998.

Fueglistaler, S., Dessler, A. E., Dunkerton, T. J., Folkins, I., Fu, Q., and Mote, P. W.: Tropical tropopause layer, Rev. Geophys., 47, RG1004, doi:10.1029/2008RG000267, 2009.

Garcia, R. R. and Solomon, S.: A new numerical model of the middle atmosphere: 2. Ozone and related species, J. Geophys. Res., 99, 12937-12951, doi:10.1029/94JD00725, 1994.

Gettelman, A., Salby, M., and Sassi, F.: Distribution and influence of convection in the Tropical Tropopause Region, J. Geophys. Res., 107, 4080, doi:10.1029/2001JD001048, 2002.

Gettelman, A., Lauritzen, P. H., Park, M., and Kay, J. E.: Processes regulating short-lived species in the tropical tropopause layer, J. Geophys. Res., 114, D13303, doi:10.1029/2009JD011785, 2009.

Hossaini, R., Chipperfield, M. P., Monge-Sanz, B. M., Richards, N. A. D., Atlas, E., and Blake, D. R.: Bromoform and dibromomethane in the tropics: a 3-D model study of chemistry and transport, Atmos. Chem. Phys., 10, 719-735, doi:10.5194/acp10-719-2010, 2010.

Iraci, L. T., Michelsen, R. R., Ashbourn, S. F. M., Rammer, T. A., and Golden, D. M.: Uptake of hypobromous acid (HOBr) by aqueous sulfuric acid solutions: low-temperature solubility and reaction, Atmos. Chem. Phys., 5, 1577-1587, doi:10.5194/acp5-1577-2005, 2005.

Kerkweg, A., Jöckel, P., Warwick, N., Gebhardt, S., Brenninkmeijer, C. A. M., and Lelieveld, J.: Consistent simulation of bromine 
chemistry from the marine boundary layer to the stratosphere - Part 2: Bromocarbons, Atmos. Chem. Phys., 8, 5919-5939, doi:10.5194/acp-8-5919-2008, 2008.

Ko, M. K. W., Poulet, G., et al.: Very short-lived halogen and sulfur substances, Scientific assessment of ozone depletion: 2002, Global Ozone Research and Monitoring Project - Report No. 47, Chapter 2, Geneva, Switzerland, 2003.

Krüger, K., and B., Quack, Introduction to special issue: the TransBrom Sonne expedition in the tropical West Pacific, Atmos. Chem. Phys. Discuss., 12, 1401-1418, 2012.

Laube, J. C., Engel, A., Bönisch, H., Möbius, T., Worton, D. R., Sturges, W. T., Grunow, K., and Schmidt, U.: Contribution of very short-lived organic substances to stratospheric chlorine and bromine in the tropics - a case study, Atmos. Chem. Phys., 8, 7325-7334, doi:10.5194/acp-8-7325-2008, 2008.

Law, K. S., Sturges, W. T., et al.: Halogenated very short-lived substances, Scientific Assessment of Ozone Depletion: 2006, Global Ozone Research and Monitoring Project - Report No. 50, Geneva, Switzerland, 2007.

Liang, Q., Stolarski, R. S., Kawa, S. R., Nielsen, J. E., Douglass, A. R., Rodriguez, J. M., Blake, D. R., Atlas, E. L., and Ott, L. E.: Finding the missing stratospheric $\mathrm{Br}_{\mathrm{y}}$ : a global modeling study of $\mathrm{CHBr}_{3}$ and $\mathrm{CH}_{2} \mathrm{Br}_{2}$, Atmos. Chem. Phys., 10, 2269-2286, doi:10.5194/acp-10-2269-2010, 2010.

Liu, C. and Zipser, E. J.: Global distribution of convection penetrating the tropical tropopause, J. Geophys. Res., 110, D23104, doi:10.1029/2005JD006063, 2005.

Livesey, N. J., Kovalenko, L. J., Salawitch, R.,J., MacKenzie, I. A., Chipperfield, M. P., Read, W. G., Jarnot, R. F., and Waters, J. W.: EOS Microwave Limb Sounder observations of upper stratospheric BrO: Implications for bromine, Geophys. Res. Lett., 33, L20817, doi:10.1029/2006GL026930, 2006.

McElroy, M. B., Salawich, R. J., Wofsy, S. C., and Logan, J. A.: Reductions of Antarctic ozone due to synergistic interactions of chlorine and bromine, Nature, 321, 759-762, 1986.

McLinden, C. A., Haley, C. S., Lloyd, N. D., Hendrick, F., Rozanov, A., Sinnhuber. B-M., Goutail, F., Degenstein, D. A., Llewellyn, E. J., Sioris, C. E., Van Roozendael, M., Pommereau, J. P., Lotz, W., Burrows, J. P.: Odin/OSIRIS observations of stratospheric BrO: Retrieval methodology, climatology, and inferred Bry, J. Geophys. Res., 115:D15308, doi:10.1029/2009JD012488, 2010.

Montzka, S. A., Reimann, S., et al.: Ozone-depleting substances and related chemicals, Scientific Assessment of Ozone Depletion: 2010, Global Ozone Research and Monitoring Project - Report No. 52, Geneva, Switzerland, 2011.

Moore, R. M., Green, C. G. and Tait, V. K.: Determination of Henry's law constants for a suite of naturally occurring halogenated methanes in seawater, Chemosphere, 30, 1183-1191, 1995.

Nielsen, J. E. and Douglass, A. R.: A simulation of bromoform's contribution to stratospheric bromine, J. Geophys. Res., 106, 8089-8100, 2001.

Nightingale, P. D., Malin, G., Law, C. S., Watson, A. J., Liss, P. S., Liddicoat, M. I., Boutin, J., and Upstill-Goddard, R. C.: In situ evaluation of airsea gas exchange parameterizations using novel conservative and volatile tracers, Global Biogeochem. Сycles, 14, 373-387, 2000.

Ordóñez, C., Lamarque, J.-F., Tilmes, S., Kinnison, D. E., Atlas, E. L., Blake, D. R., Sousa Santos, G., Brasseur, G., and
Saiz-Lopez, A.: Bromine and iodine chemistry in a global chemistry-climate model: description and evaluation of very short-lived oceanic sources, Atmos. Chem. Phys., 12, 14231447, doi:10.5194/acp-12-1423-2012, 2012.

Pisso, I., Haynes, P. H., and Law, K. S.: Emission location dependent ozone depletion potentials for very short-lived halogenated species, Atmos. Chem. Phys. 10, 12025-12036, 2010.

Quack, B. and Wallace, D. W. R.: Air-sea flux of bromoform: Controls, rates and implications, Global Biogeochem. Cy. 17, 1023, doi:10.1029/2002GB001890, 2003.

Quack, B., Atlas, E., Petrick, G., Stroud, V., Schauffler, S., and Wallace, D. W. R.: Oceanic bromoform sources for the tropical atmosphere, Geophys. Res. Lett., 31, L23S05, doi:10.1029/2004GL020597, 2004.

Quack, B., Atlas, E., Petrick, G., and Wallace, D. W. R.: Bromoform and dibromomethane above the Mauritanian upwelling: Atmospheric distributions and oceanic emissions, J. Geophys. Res., 112, D09312, doi:10.1029/2006JD007614, 2007.

Salawitch, R. J.: Atmospheric chemistry: Biogenic bromine, Nature, 439, 275-277, doi:10.1038/439275a, 2006.

Salawitch, R. J., Weisenstein, D. K., Kovalenko, L. J., Sioris, C. E., Wennberg, P. O., Chance, K., Ko, M. K. W., and McLinden, C. A.: Sensitivity of ozone to bromine in the lower stratosphere, Geophys. Res. Lett., 32, L05811, doi:10.1029/2004GL021504, 2005.

Salawitch, R. J., Canty, T., Kurosu, T., Chance, K., Liang, Q., da Silva, A., Pawson, S., Nielsen, J. E., Rodriguez, J. M., Bhartia, P. K., Liu, X., Huey, L. G., Liao, J., Stickel, R. E., Tanner, D. J., Dibb, J. E., Simpson, W. R., Donohoue, D., Weinheimer, A., Flocke, F., Knapp, D., Montzka, D. D., Neuman, J. A., Nowak, J. B., Ryerson, T.B., Oltmans, S., Blake, D. R., Atlas, E. L., Kinnison, D. E., Tilmes, S., Pan, L. L., Hendrick, F., Van Roozendael, M., Kreher, K., Johnston, P. V., Gao, R. S., Johnson, B., Bui, T. P., Chen, G., Pierce, R. B., Crawford, J. H., and Jacob, D. J.: A New interpretation of total column BrO during Arctic spring, Geophys. Res. Lett., 37, L21805, 2010.

Schauffler, S. M., Atlas, E. L., Flocke, F., Lueb, R. A., Stroud, V., and Travnicek, W.: Measurements of bromine containing organic compounds at the tropical tropopause, Geophys. Res. Lett., 25, 317-320, 1998.

Schauffler, S. M., Atlas, E. L., Blake, D. R., Flocke, F., Lueb, R. A., Lee-Taylor, J. M., Stroud, V., and Travnicek, W.: Distributions of brominated organic compounds in the troposphere and lower stratosphere, J. Geophys. Res., 104, 21513-21535, 1999.

Sinnhuber, B.-M., Arlander, D. W., Bovensmann, H., Burrows, J. P., Chipperfield, M. P., Enell, C.-F., Frieß, U., Hendrick, F., Johnston, P. V., Jones, R. L., Kreher, K., Mohamed-Tahrin, N., Müller, R., Pfeilsticker, K., Platt, U., Pommereau, J.-P., Pundt, I., Richter, A., South, A. M., Tørnkvist, K. K., Van Roozendael, M., Wagner, T., and Wittrock, F.: Comparison of measurements and model calculations of stratospheric bromine monoxide, J. Geophys. Res., 107, 4398, doi:10.1029/2001JD000940, 2002.

Sinnhuber, B.-M. and Folkins, I.: Estimating the contribution of bromoform to stratospheric bromine and its relation to dehydration in the tropical tropopause layer, Atmos. Chem. Phys., 6, 4755-4761, doi:10.5194/acp-6-4755-2006, 2006.

Sinnhuber, B.-M., Rozanov, A., Sheode, N., Afe, O. T., Richter, A., Sinnhuber, M., Wittrock, F., Burrows, J. P., Stiller, G. P., von Clarmann, T., and Linden, A.: Global observations of strato- 
spheric bromine monoxide from SCIAMACHY, Geophys. Res. Lett., 32, L20810, doi:10.1029/2005GL023839, 2005.

Sioris, C. E., Kovalenko, L. J., McLinden, Salawitch, R. J., Van Roozendael, M., Goutail, F., Dorf, M., Pfeilsticker, K., Chance, K., von Savigny, C., Liu, X., Kurosu, T. P., Pommereau, J.P., B ̈̈ch, H., and Frerick, J.: Latitudinal and vertical distribution of bromine monoxide in the lower stratosphere from Scanning Imaging Absorption Spectrometer for Atmospheric Chartography limb scattering measurements, J. Geophys. Res., 111, D14301, doi:10.1029/2005JD006479, 2006.

Solomon, S., Wuebbles, D. J., Isaksen, L., Kiehl, J., Lal, M., Simon, P., and Sze, N.: Ozone depletion potentials, global warming potentials, and future chlorine/bromine loading, Scientific assessment of ozone depletion: 1994, Global Ozone Research and Monitoring Project Report No. 37, World Meteorological Organization, Geneva, Switzerland, 13.1-13.36, 1995.

Spichtinger, N., Wenig, M., James, P., Wagner, T., Platt, U., and Stohl, A.: Satellite detection of a continental-scale plume of nitrogen oxides from boreal forest fires, Geophys. Res. Lett., 28, 4579-4582, 2001.

Stohl, A., Forster, C., Eckhardt, S., Spichtinger, N., Huntrieser, H., Heland, J., Schlager, H.,Wilhelm, S., Arnold, F., and Cooper, O.: A backward modeling study of intercontinental pollution transport using aircraft measurements, J. Geophys. Res., 108, 4370, doi:10.1029/2002JD002862, 2003.

Stohl, A. and Thomson, D. J.: A density correction for Lagrangian particle dispersion models, Bound.-Layer Meteorol., 90, 155$167,1999$.

Stohl, A. and Trickl, T.: A textbook example of long-range transport: Simultaneous observation of ozone maxima of stratospheric and North American origin in the free troposphere over Europe, J. Geophys. Res., 104, 30445-30462, 1999.

Stohl, A., Hittenberger, M., and Wotawa, G.: Validation of the Lagrangian particle dispersion model FLEXPART against large scale tracer experiment data, Atmos. Environ., 32, 4245-4264, 1998.

Stohl, A., Forster, C., Frank, A., Seibert, P., and Wotawa, G.: Technical note: The Lagrangian particle dispersion model FLEXPART version 6.2, Atmos. Chem. Phys., 5, 2461-2474, doi:10.5194/acp-5-2461-2005, 2005.
Tokarczyk, R. and Moore, R.: Production of volatile organohalogens by phytoplankton cultures, Geophys. Res. Lett., 21, p. 285, doi:10.1029/94GL00009, 1994.

von Glasow, R., von Kuhlmann, R., Lawrence, M. G., Platt, U., and Crutzen, P. J.: Impact of reactive bromine chemistry in the troposphere, Atmos. Chem. Phys., 4, 2481-2497, doi:10.5194/acp-42481-2004, 2004.

Wamsley, P. R., Elkins, J. W., Fahey, D. W., Dutton, G. S., Volk, C. M., Myers, R. C., Montzka, S. A., Butler, J. H., Clarke, A. D., Fraser, P. J., Steele, L. P., Lucarelli, M. P., Atlas, E. L., Schauffler, S. M., Blake, D. R., Rowland, F. S., Sturges, W. T., Lee, J. M., Penkett, S. A., Engel, A., Stimpfle, R. M., Chan, K. R., Weisenstein, D. K., Ko, M. K. W., and Salawitch, R. J.: Distribution of halon-1211 in the upper troposphere and lower stratosphere and the 1994 total bromine budget, J. Geophys. Res., 103, 15131526, doi:10.1029/97JD02466, 1998.

Warwick, N. J., Pyle, J. A., Carver, G. D., Yang, X., Savage, N. H., O'Connor, F. M., and Cox, R. A.: Global modeling of biogenic bromocarbons, J. Geophys. Res., 111, D24305, doi:10.1029/2006JD007264, 2006.

Wuebbles, D. J., Patten, K. O., Wang, D., Youn, D., Martí nezAvilés, M., and Francisco, J. S.: Three-dimensional model evaluation of the Ozone Depletion Potentials for n-propyl bromide, trichloroethylene and perchloroethylene, Atmos. Chem. Phys., 11, 2371-2380, doi:10.5194/acp-11-2371-2011, 2011.

Yang, X., Cox, R. A., Warwick, N. J., Pyle, J. A., Carver, G. D., O'Connor, F. M., and Savage, N. H.: Tropospheric bromine chemistry and its impacts on ozone: A model study, J. Geophys. Res., 110, D23311, doi:10.1029/2005JD006244, 2005.

Yang, X., Pyle, J. A., Cox, R. A., Theys, N., and Van Roozendael, M.: Snow-sourced bromine and its implications for polar tropospheric ozone, Atmos. Chem. Phys., 10, 7763-7773, doi:10.5194/acp-10-7763-2010, 2010.

Yokouchi, Y., Hasebe, F., Fujiwara, M., Takashima, H., Shiotani, M., Nishi, N., Kanaya, Y., Hashimoto, S., Fraser, P. J., ToomSauntry, D., Mukai, H., Nojiri, Y.: Correlations and emission ratios among bromoform, dibromochloromethane, and dibromomethane in the atmosphere, J. Geophys. Res. 110, D23309, doi:10.1029/2005JD006303, 2005. 